\title{
ANTECEDENTES Y CARACTERIZACIÓN DE LA METROPOLIZACIÓN DEL VALLE DE ABURRÁ (COL)
}

\author{
Jaime Enrique Rodríguez Navas \\ Magíster en Derecho Público, Convenio Universidad Santo Tomás-Universidad de Konstanz-Alemania; Especialista \\ en Derecho Administrativo, Universidad Santo Tomás, Bucaramanga (Col); Especialista en Derecho Minero y \\ Energético, Universidad Externado de Colombia (Col); Especialista en Derecho Público, Convenio Universidad \\ Externado de Colombia-Universidad Autónoma de Bucaramanga UNAB \\ Docente Universidad Santo Tomás- Bucaramanga (Col). \\ E-mail: jaimeenriquerodrigueznavas@yahoo.es
}

\section{Resumen}

Este trabajo es producto de la investigación la ingobernabilidad de las áreas metropolitanas: un problema de etiología normativa que desarrolla el grupo Derecho Público de la Universidad Santo Tomás de Bucaramanga. Delinea, con sujeción a los textos de los más connotados historiadores y cultores del urbanismo antioqueños, y con apoyo en la estadística oficial, el rastro de la metropolización del Valle de Aburrá, como un proceso que aunque hizo explosión a mediados del siglo XX, parecía determinado desde los primeros poblamientos por la dinámica integradora de los flujos económicos de los pueblos establecidos a lo largo del valle, que seguía la fuerza y el trazado articulador del río del que heredó su nombre. Se propone connotar las ventajas que ha representado esta vocación integradora en la conformación de arreglos necesarios para el gobierno del área metropolitana, y sienta las bases que permitirán evidenciar, por contraste, en un estado ulterior de la investigación, las asimetrías de los cinco primeros procesos de metropolización que se dieron en Colombia.

Palabras Clave: Las áreas metropolitanas, la integración, la gobernanza, la ciudad de gobierno, metropolización, un-gobierno

\begin{abstract}
This work is the result of an investigation about "un-governance of metropolitan areas: a problem of normative etiology" which is researched by the Public Law Group of the University of Saint Tomas Bucaramanga Campus. It delineates, with consideration of the texts of the most renowned historians and urban planners from Antioquia, and with support of the official statistics, and the traces of the metropolization in the Valley of Aburra, as a process that started half way of the twentieth century, which seemed oriented from the very first settlements and their dynamic integration of their economic ties along the valley. This proposes to highlight the benefits from this integration process, and the necessary fix up for the government in the metropolitan area, and establishes the bases that allows to pin point evidence, in contrast to, in a more advance state of the research, the asymmetries of the first five metropolization processes that happened in Colombia.
\end{abstract}

Key Words: Metropolitan areas, integration, governance, town governance, metropolization, un-governance

\section{Résumé}

Ce travail est le résultat de l'enquête "ingouvernabilité des régions métropolitaines: un problème de règles etiology" développés par le groupe de droit public Université St. Thomas de Bucaramanga. Outlines, sous réserve des textes de grands représentants des historiens urbains et d'Antioquia, et pris en charge dans les statistiques officielles, la trace de la métropolisation Aburrá vallée, comme un processus, mais a explosé dans le milieu du XXe siècle, il semblait déterminé à partir des premiers établissements par l'intégration dynamique des flux économiques de personnes se sont installées le long de la vallée, à la suite de la force chemin et articulateur de la rivière à partir de laquelle a hérité de son nom. Il est proposé pour connoter les avantages qui a représenté cette intégrationniste dans l'élaboration de dispositions gouvernementales pour la région métropolitaine, et jette les bases qui montrent, en revanche, dans une enquête état ultérieur, les asymétries des cinq premiers processus métropolisation qui a eu lieu en Colombie.

Mots-clés: Les régions métropolitaines, l'intégration, la gouvernance, l'administration municipale, Metropolis, un-gouvernement 

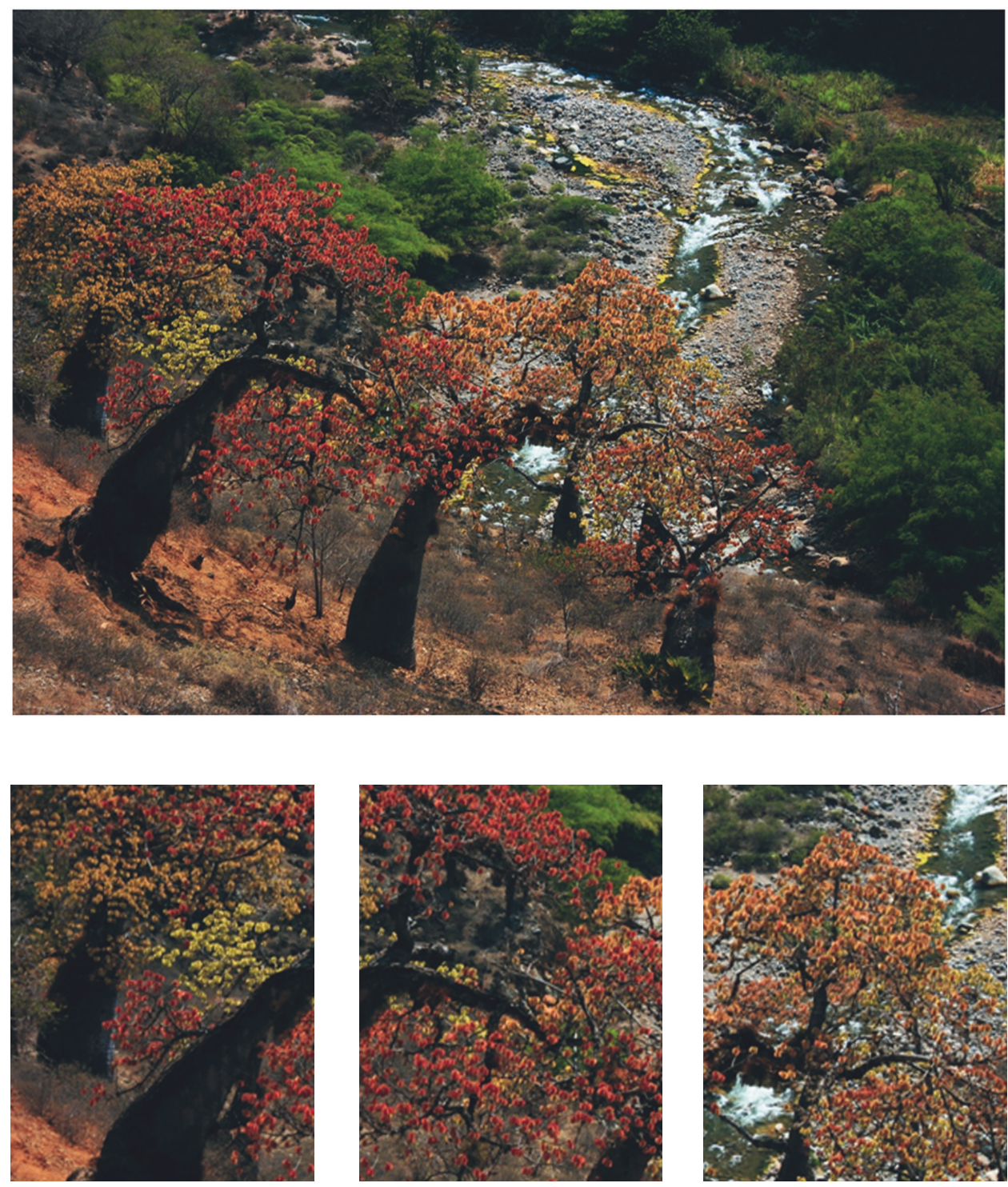

Cañón del Chicamocha - Ceibas Barrigonas

Jorge William Sánchez Latorre 


\section{ANTECEDENTES Y CARACTERIZACIÓN DE LA METROPOLIZACIÓN DEL VALLE DE ABURRÁ (COL)*}

Jaime Enrique Rodríguez Navas

\section{INTRODUCCIÓN}

El trabajo de delinear los principales trazos de un proceso de metropolización en Colombia, bien podría recogerse a un periodo de sesenta años contados retrospectivamente desde la actualidad. Sin embargo, se ha considerado de interés el seguimiento de los rastros dejados por el poblamiento de las regiones materia de estudio desde los primeros registros de información que se tengan, perspectiva que se remite en algunos casos al periodo precolombino y, en otros, hasta las primeras expediciones de la conquista, según sea el impacto que ha dejado en la sociología de sus gentes la cultura indígena.

Para el caso del Valle de Aburrá, son varios los factores que eximen a este grupo de investigación de mayores referencias al periodo precolombino, entre otras, el feroz exterminio de la población aborigen que resistió a las huestes de conquista y el descarnado empleo que se hizo de la mano de obra indígena en la explotación de la minería durante la colonia y aunque en menor escala, durante buena parte de su vida republicana. Uno y otro factor determinaron la desaparición de la cultura aborigen, de la que sólo nos quedó la huella que en algunos casos puede rastrearse en la toponimia.

* El artículo es producto de la Investigación Ingobernabilidad de las Áreas Metropolitanas: un problema de etiología normativa. - Cuarta Convocatoria Interna USTA Bucaramanga 2010, adelantada por el autor. Grupo de Investigación Derecho Público USTA Bucaramanga, Línea de Investigación, Aministración y Gobierno del Estado Social de Derecho, Facultad de Derecho. 
Mayor importancia cobra el estudio de las formas que tomó el poblamiento, muchas veces disperso e irregular del territorio, así como la consideración de la incidencia que tuvieron las actividades económicas preponderantes sobre los procesos de ocupación de un suelo, como el del Valle de Aburrá, determinado por el cauce del río del mismo nombre, y limitado por las cuencas de las quebradas que en él vertían sus aguas, poblamiento que desde sus orígenes estuvo signado por una vocación de unidad que dejó huella, y que llevó, como de la mano, a los poblados asentados en el valle, a un resultado de integración, que se hizo conurbado como consecuencia del influjo que sobre el comercio y la laboriosidad de los residentes ejerció el arribo que a estas tierras hizo en la vida republicana, después de mediados del siglo XIX, el oleaje periférico del capitalismo, con sus relaciones de producción de corte fordista (Betancur, et al., 01) .

La decadencia de la industria de ese corte, ocurrida a partir de los años 60, la consiguiente reconversión de la actividad económica (Giraldo, 2008) y los rezagos que uno y otro hecho dejaron en la pirámide social, también incidieron en la forma urbana, y aceleraron una manera problemática de conurbación que hoy, merced a las fuerzas de la globalización, se extiende allende el Valle de Aburrá para dar forma a una especie de región metropolitana por integración de los valles de San Jerónimo, san Nicolás y de Aburrá, constituyendo un reto al que se pretende responder desde el accionar una institucionalidad inspirada en el asociacionismo, cuyos primeros frutos alcanzan a documentarse en esta revisión.

\section{EL VALLE DE ABURRÁ EN LA PROVINCIA DE ANTIOQUIA}

El actual departamento de Antioquia en cuyo territorio central se asienta el Valle de Aburrá, tiene una extensión de 63.612 kilómetros cuadrados, su relieve es altamente montañoso por cuanto su territorio es recorrido de norte a sur por las cordilleras central y occidental. Ésta separa los valles de los ríos Cauca y Atrato, al tanto que aquella separa los valles de los ríos Cauca y Magdalena (Encarta ${ }^{\circ}$ Online 2009).

Sus tierras costeras en el Golfo de Urabá formaron parte de las primeras rutas de saqueo que transitaron los conquistadores en Colombia en los primeros años del siglo XVI, y en ellas se estableció San Sebastián de Urabá, la primera población no aborigen, aunque de efímera existencia, en suelo colombiano. Allende las costas, la exploración tierra adentro durante los tres primeros decenios del siglo XVI, estuvo motivada por la búsqueda del oro de los aborígenes (Melo, 1987).

Los primeros poblamientos españoles formales en los Andes antioqueños se establecieron en el Valle del Río Cauca, al occidente del actual departamento de Antioquia, que deriva su nombre del que recibió la primera población fundada en dicho valle en diciembre de 1541. La segunda fue Santa Fe, fundada en 1546. Estas dos poblaciones, que fueron unificadas probablemente en 1549 bajo el nombre de Santa Fe de Antioquia, fungieron como base de un fecundo proceso de colonización 
española que dio base, a su vez, a la institución de la encomienda, medio útil para la distribución de los pocos indígenas que sobrevivieron al genocidio provocado por la fiebre del oro, y que en principio fueron empleados al servicio de la economía minera que se prodigó en el occidente y que hasta finales del siglo se extendió hacia el nordeste del departamento, región en la que se fundaron otras poblaciones entre las que se destacan Remedios, Zaragoza, Francisco la Antigua de Guamocó y Cáceres (Ibídem).

Las tierras relativamente planas, localizadas al sur de la región central del actual departamento de Antioquia, recorridas de norte a sur a lo largo de sus casi sesenta (60) kilómetros de extensión por un río que los habitantes raizales de allí denominaban Aburrá, fueron visitadas fugazmente, por primera vez, hacia 1541 por las huestes de Jorge Robledo al mando de Luis Tejelo, que soportaron la fiera oposición de los nativos (Robledo, 1945).

Desde entonces, el valle de Aburrá, o de San Bartolomé como lo denominaron los españoles, fue visitado con alguna frecuencia por huestes españolas que pretendían domeñar a los indígenas belicosos que las habitaban, y con el tiempo y en la medida en que estas expediciones resultaron exitosas, fue objeto de reparto y dio lugar a la formación de haciendas de gran extensión en torno a las cuales se surtió un proceso de poblamiento disperso alrededor de las actividades económicas emprendidas por vecinos de Santa Fe de Antioquia en los ramos de la agricultura, la ganadería de la pequeña minería, así como del comercio que surgía merced al tránsito que por allí se daba camino de otras zonas como Guarne, Río Negro, Las Moscas y Piedras Blancas (Correa, 2008).

Ejemplo ilustre de estos repartos se encuentra en la concesión que se hizo por el Cabildo de Antioquia, con la venia del Gobernador de Popayán, en el año de 1574, a Gaspar de Rodas, conquistador que participó activamente en la reubicación de Santa Fe (la de Antioquia) bajo las órdenes de Belalcázar, quien tenía en esa ciudad propiedades y repartimientos de indios, y había sido comisionado en varias oportunidades para someter las sublevaciones de los nativos de diferentes partes de la provincia (Acosta, 1883), de "tres leguas de tierra yerma y despoblada", en el Valle de Aburrá, y en tierras del actual Guayabal, como quiera que se indicó en el título de concesión, que se ubicaba "tres cuartos de legua al sur del cerrito redondo que está en medio del Valle", esto es, del cerro que hoy llamamos Nutibara (García, 1988).

Sobre tierras de esta hacienda, que para entonces pertenecían al hato de Bartolomé de Alarcón, y por disposición del primer visitador y oidor oficial de la Corona, Francisco de Herrera y Campuzano, se fundó en 1616 el pueblo de indios de San Lorenzo como ejecución de la cédula real que ordenaba la reducción de los indios para su mejor adoctrinamiento y para mejor protección de la población indígena supérstite a la explotación en la industria minera (Escobar, 2004), poblado que fue trasladado treinta años después a un sitio angular entre los vectores del Río Aburrá y la quebrada Santa Elena, siendo reconocida, tres años más tarde y por causa del nombre signado para el templo allí construido, como poblado de Nuestra Señora de la Candelaria de Aná. (Londoño, 1965). 
A su lado, y a lo largo del recorrido del Río por el valle, se formaron desde el último cuarto del siglo XVI, pequeñas agrupaciones espontáneas de personas y de construcciones en torno de la actividad desplegada en algunas de las haciendas y hatos que allí se establecieron, dando forma, por el lado oriental del Río Aburrá a los pequeños caseríos de Barbosa, Girardota, y Copacabana; y por la margen occidental, a los poblados de Hatoviejo (hoy Bello), La Culata, Guayabal e Itagüí (Melo, 1987).

\section{LA VILLA DE LA CANDELARIA DE MEDELLÍN}

Hacia 1675, como resultado de las gestiones adelantadas en la Península por una nueva élite económica con intereses vinculados a la ganadería, al agro y al comercio, diferentes de los propios de la actividad minera de la dirigencia de la capital de la provincia, se fundó formalmente y mediante Cédula Real de 24 de noviembre de 1674, la Villa de Nuestra Señora de la Candelaria de Medellín (Restrepo, 1987) bajo la previsión de no permitir, en el curso de diez años, que en esta villa tomaran asiento los vecinos de la ciudad de Antioquia a fin de evitar su despoblamiento, previsión que hacía eco de las prevenciones de las élites de esa ciudad hacia el futuro promisorio de la naciente villa.

La ejecución de la cédula real estuvo a cargo del Gobernador de la Provincia, quien escogió por sitio para la erección de la villa las tierras en las que se asentaba la población de Nuestra Señora de la Candelaria de Aná, previó en un primer trazado urbano la existencia de un caserío de sesenta y cuatro cuadras, ocho a lo largo y ocho a lo ancho, y delimitó la jurisdicción de la villa, "desde los nacimientos de dicho Río (Medellín), hasta donde entra el Río Porce, de una banda a otra, hasta la cumbre". (Londoño, 1965)

Dos aspectos convienen connotar en las circunstancias de la fundación de la Villa. El primero, que presenta una particularidad respecto de la tendencia característica en la Colonia, y es que no fue situada sobre campo raso, en tierras vacías escogidas para el efecto, sino que se retomó un sitio ya habitado, que forzó el desplazamiento de sus habitantes, de los predios sobre los que se asentaría el marco de la plaza (Perfetti, 1996). El segundo, la jurisdicción que para las autoridades de la Villa delimitó el Gobernador, constituye un elemento tempranamente premonitorio de la conformación del área Metropolitana del Valle de Aburrá.

La dinámica exponencial de la economía fundada en el comercio que desarrollaban los vecinos de la Villa de la Candelaria en contacto directo con los centros internacionales de despacho obviando la intermediación del comerciante radicado en Santa Fe de Bogotá; la crisis de la minería, la consiguiente decadencia de Santa Fe de Antioquia; las ventajas que derivó la nueva Villa de La Candelaria de su condición de medianía entre los centros de disputa política de Cartagena y Popayán, la abundancia de fuentes hídricas, las facilidades que ofrecía para la extracción de arena y piedra como materiales de construcción, la existencia de un clima medio, las ventajas que para la agricultura representaba su altura media sobre el nivel del 
mar, la abundancia de pastos, la posibilidad del empleo del Río Porce como ruta de abastecimiento de los centros mineros del Norte (Corantioquia, 2005), y su condición de punto geográfico en el que interconectaban el Occidente y el Oriente antioqueño fueron, a su vez, factores determinantes de la prolífica colonización del Valle de Aburrá, en cuyo centro obraba la fuerza motriz del optimismo y el tesón de los habitantes de la nueva Villa de la Candelaria, la fuerza del sueño de ciudad y el consiguiente atractivo para la inmigración de los capitales regionales, (Twinam, 1985) con beneficio de todos los sitios y poblados circunvecinos del valle de Aburrá, entre los que se contaban Hato Viejo, Guayabal, La Culata, e Itagüí, y de Río Negro, en la puerta del oriente antioqueño.

A lo largo del siglo XVII, la Villa de la Candelaria y el valle de Aburrá como un conjunto crecieron en forma significativa, entre otras razones porque Medellín experimentaba un activo flujo migratorio de doble vía, pues al tiempo que recibía nuevos habitantes procedentes en su mayoría de otras partes de Antioquia, se exportaban otros tantos, en mayor medida hacia el resto del Valle y en menor escala hacia nuevos centros de colonización.

Las estadísticas comparadas de los censos de 1675 y 1786 muestran que la naciente Medellín, sin fungir aún como capital política y administrativa de la provincia de Antioquia y sin contar, por consiguiente, con la energía dinamizadora de la vida burocrática, vio crecer cinco veces su población, a una tasa del $1.54 \%$ anual, y que el Valle, en su conjunto, que había sumado tres mil personas organizadas en aproximadamente doscientas ochenta y ocho (288) familias en 1675, totalizaba dieciséis mil doscientos sesenta y cuatro (16.264) habitantes en 1786, concentrándose allí la tercera parte de la población de la provincia. Muestra también este dinamismo, el que veinte (20) años después, en 1808, el valle contara ya con treinta mil novecientos ochenta y dos habitantes, de los cuales, casi la mitad se asentaban en Medellín, y que en el mismo periodo, el número de casas de teja construidas en Medellín ascendiera de 242 a 360 (Álvarez, 1996).

Para la época de la independencia, Antioquia tenía tres regiones pobladas y dotadas de asentamientos formales y económicamente activos: la región norte, en la que fulgían Cáceres, Zaragoza y Nechí; en el oriente, lideraban Río Negro y Marinilla: y al centro contaba con la decadente Santa Fe de Antioquia y la pujante Medellín, que se comunicaba activa y prolíficamente con el Norte por el cauce del Río Porce que enlazaba comercialmente a la capital de la Provincia con el oriente y se convertía, cada vez más, en el canal a través del cual la Provincia se comunicaba con el exterior.

En los albores de los tiempos de la independencia, la pujante Medellín empezaba a diferenciarse ligeramente de las poblaciones vecinas del Valle, pues contaba con dos iglesias (Nuestra Señora de la Candelaria- ubicada a un costado de la plaza principal-, la Iglesia de la Veracruz - construida en el cruce de la Carabobo con Boyacá-), hospital, cárcel, fábrica de aguardiente, mejores servicios y comunicaciones que aquellas. Acusaba, además, las secuelas de un desarrollo 
temprano, pues el incremento de artesanos y gentes pobres empezaba a configurar espacios delineados sin consideración a las disposiciones urbanísticas de la colonia en los que las construcciones precarias se apiñaban alrededor de vías más estrechas que de costumbre al seguir el trazado de algunas fuentes hídricas. Tal era el caso de las gentes agrupadas en El Camellón o en los entornos de la Toma del acueducto (Melo, 1987)

Los aires republicanos vinieron muy bien a Medellín. En la primera república, aunque bajo el tiempo de dictadura de Del Corral, Medellín fue reconocida como ciudad en consideración a los importantes servicios prestados a la Patria (Medina, 84), y tan sólo trece años después, con ocasión de la modificación de la ley de ordenamiento territorial de 1824, se radicó la capitalía de la Provincia de Antioquia en la ciudad de Medellín, capital también del Cantón de Medellín al que pertenecían las parroquias de Titiribí, Amagá, La Estrella, Envigado, Belén, San Cristóbal y Copacabana; y al que pertenecerían, dos años después, las parroquias de Aná, Barbosa, Heliconia, Fredonia, Hatoviejo, Itagüí y Girardota (Rendón, 97). Esta capitalía, combinó la centralidad económica que había capitalizado la ciudad en los últimos cincuenta años, con la centralidad burocrática, que hacía mucho más atractiva la ciudad para propios y extraños, e intensificaba consiguientemente la concentración demográfica en términos que permitieron que entre 1850 y 1870 la población de Medellín se duplicara (Schnitter, 2006), se rompió así la tendencia ya observada al relativo equilibrio que en materia de ocupación territorial habían guardado hasta entonces las poblaciones del Valle, en términos que se intensificarían con la industrialización que experimentó Medellín a finales del siglo XIX y principios del XX.

Ese crecimiento poblacional determinó, a lo largo del siglo XIX, una expansión longitudinal del casco urbano en dirección nororiental sin consideración del obstáculo natural que representaba la quebrada Santa Elena, que hubo de ser superada mediante el tendido de puentes sobre su cauce para dar continuidad a las vías históricas que corrían en sentido sur norte, en especial, las carreras Junín (49), Palacé (50) y Bolívar (51), hasta hacer de ella el eje de la ciudad.

A finales del siglo esta expansión avanzó en torno de la plaza Simón Bolívar construida en predios donados por el británico Stuart Moore para acompañar, como era costumbre, la edificación en tránsito de la nueva catedral en torno de la cual surgió el barrio Villanueva camino de El Prado en porfiado avance hacia terrenos de ladera (Melo, 1987).

\section{INDUSTRIALIZACIÓN Y MODERNIZACIÓN DE LA VILLA}

Muy a pesar de la perspectiva que aquí se ha observado para explicar el crecimiento y desarrollo de la ciudad como resultado de factores de variada índole, entre quienes han señalado con especial insistencia el geográfico y el económico, ha de reconocerse 
que en la vida de los pueblos suelen aparecer personalidades paradigmáticas que reflejan en su personalidad y en sus ejecutorias, como a bien tenga ver cada quien, o las virtudes y defectos del pueblo del que emergen, o simplemente las oportunidades y amenazas de su tiempo y su compleja realidad próxima

Tal es el caso de Pedro Justo Berrío un hombre que, en medio de las guerras civiles que azotaron a la República y al Estado de Antioquia, cabalgó con ventura sobre las dinámicas de lo público y lo privado que se gestaban en Antioquia y contribuyó notablemente al moldeado de un espíritu de modernidad en los mineros, comerciantes, ganaderos y agricultores antioqueños y en particular medellinenses, que habría de influir de manera significativa en su desarrollo próximo.

La sola cita de sus mejores ejecutorias en los diez últimos años de su corta vida, como que murió a los cuarenta y ocho años, es suficiente para explicar esta sección del país. Desarrolló un ambicioso programa de escuelas y caminos, estableció la imprenta y la Biblioteca del Estado, tendió el primer telégrafo, creó la Escuela de Artes y Oficios, y la Escuela Normal de Institutores, organizó las sociedades de fomento (en agricultura, beneficencia, comercio, instrucción pública y salubridad) en casi todos los distritos de Antioquia, organizó la policía y la administración del servicio de salud por el Estado, lideró la creación del Banco de Antioquia, impulsó la colonización de baldíos y la construcción de un camino carreteable entre Medellín y el río Magdalena cuyo trazado sirviera para delinear la huella de un futuro ferrocarril (Molina), con lo cual prefiguró el Ferrocarril de Antioquia, servicio llamado a marcar gran parte de la historia no sólo de Medellín, sino del Estado antioqueño.

Pero Berrío es tan sólo una muestra, muy emblemática sí, del espíritu que inspiró el enriquecido entramado de relaciones existente en el último cuarto de siglo XIX entre el sector público y el privado en Antioquia, pero especialmente en Medellín, cuyas élites, aprovechadas hábilmente las nuevas relaciones comerciales que surgieron con Inglaterra después de la independencia, recibieron los beneficios de las políticas librecambistas incubadas en la república después de los años 60 (Palacios, 1999), y aplicaron los excedentes de la decadente actividad minera, y de la reciente y próspera explotación del café, que había entrado en Santander, pero que había mudado a la próspera Antioquia para huir del fulgor definidor de la guerra de los mil días, a los nuevos renglones de la banca y la industria que incursionaban en la economía nacional, que generaba una nueva y acelerada dinámica que empezó a gravitar "en función al ritmo y exigencias del gran centro urbano" (Schnitter, 2006), con detrimento de los demás municipios del Valle de Aburrá.

Este movimiento de modernización en materia económica tuvo su correlato en materia urbanística de la mano del "higienismo", tendencia que respondía a las exigencias que en materia de salubridad pública planteaba el crecimiento de la ciudad. Bajo su égida en 1890 se aprobó el primer plano de Medellín Futuro, cuyos principales lineamientos se orientaban especialmente hacia la formulación de programas de "domesticación" del agua, unas veces por la vía de la desecación de pantanos, otras por la del control y prevención de inundaciones, y otras más por la 
de la conducción higiénica del agua desde sus fuentes hasta los centros urbanos de consumo; y a la formulación de proyectos ordenados al uso prolífico del aire y del sol mediante la ampliación del ancho de las calles para facilidad de la circulación, tanto del aire, como de la luz, de las aguas servidas y del tráfico de personas y medios de comunicación terrestre. (González, 2007).

Mientras el mejor uso del aire y el sol movió a repensar las dimensiones que debían tener las vías y los espacios públicos de esparcimiento, la "domesticación" del agua se centró, especialmente, sobre la transformación y modernización de la infraestructura de servicios públicos y la rectificación del cauce y la estabilización de laderas del Río Medellín, y subsiguientemente sobre el cubrimiento progresivo de las dos grandes corrientes hídricas que acunaron a la ciudad en su fundación, el río y la quebrada Santa Elena.

En el primer ámbito, operó, de una parte, la municipalización y repotenciación del servicio de energía eléctrica, factor que permitió la alimentación energética de los nuevos desarrollos industriales y del tranvía, y de otra, la sustitución de las vetustas redes de barro modernas tuberías de hierro y la localización de los tanques de almacenamiento en el nororiente de la ciudad, hecho que atrajo a partir de los años 20 el crecimiento urbanístico de la ciudad, desde los contornos de lo que hoy se reconoce como el centro, hacia la ladera nororiental, impulsando el desarrollo de los barrios Manrique, Sucre, Buenos Aires y El Salvador (, 2000).

En el segundo ámbito, se dio inicio a las labores de rectificación del cauce y del papel que cumplían el Río y las quebradas, elementos estructurantes del desarrollo regional del Valle de Aburrá, que desde por lo menos los años 20 de la pasada centuria habían dejado de obrar como atractivos turísticos para convertirse en antihigiénicas corrientes visibles de aguas negras.

Esta contaminación obedeció, en buena medida, a la incursión que hizo el Valle de Aburrá, como parte de Antioquia, desde los albores del siglo XX, en un proceso de industrialización que otras zonas del país sólo conocerían a partir del tercer decenio de ese siglo.

Ello permitió que la ciudad capital creciera al ritmo de sus industrias, bajo el apremio de las necesidades originadas en la inmigración de la población obrera que dicho proceso demandó, y de la mano de la conjugación de intereses públicos y privados que se dio en el ámbito urbanístico en torno de la Sociedad de Mejoras Públicas, entidad de la cual formaron parte los primeros urbanizadores de la época y que influyó notablemente en las decisiones que en materia de salubridad, higiene, embellecimiento, obras públicas y urbanismo adoptó el Concejo Municipal (entre las que sobresale la adopción del segundo plano futuro de la ciudad y la municipalización del servicio de energía eléctrica) y en las que en su ramo adoptaron, más tarde, las Empresas Municipales, después denominadas Empresas de Servicios Públicos de Medellín (Correa, 2009).

Su papel estelar en el desarrollo de Medellín a lo largo de los primeros cincuenta años del siglo XX (después cedería su protagonismo a Valorización), se resume en el 
siguiente recuento de actuaciones: presentación a la Municipalidad del primer Plan de aguas y alcantarillados; integración de la Junta que promovió la canalización del río Medellín, suministro de los primeros bancos para plazas y parques públicos, formulación de las bases para la expedición del Código de Urbanización, introducción, con fondos propios de las primeras obras de la construcción del campo de aterrizaje; orientación del proceso de adquisición de los terrenos para la construcción de la plaza de ferias; establecimiento de la primera flota de coches públicos, entre otras (Coupé, 1993).

El impacto del proceso de industrialización trascendió, por supuesto, los contornos de la ciudad central del Valle. Ya para la primera mitad del siglo XX se ha dicho que "una observación general de la actividad económica (...), muestra que a excepción del municipio de la Estrella, en los demás municipios del valle tuvo asiento la industria que afectó de manera diferente cada municipio. En los cercanos a Medellín, Envigado e Itagüí al sur y Bello al norte, la industria tuvo un gran impacto con las textileras, que recibieron gran cantidad de población inmigrante, una gran proporción de mujeres, sin embargo, en los otros municipios: Caldas, Sabaneta, Copacabana, Girardota y Barbosa se tuvo una incidencia menos determinante. Se puede decir que en alguna medida la industria desconcentró la actividad de Medellín, los inmigrantes que llegaban al valle pudieron obtener un trabajo en las fábricas de los demás municipios, éstas tuvieron un papel predominante en su desarrollo por la función social que desempeñaron: acompañaron a los municipios en su función pública al ofrecer servicios de salud, vivienda, educación, servicios de agua, luz y alcantarillado. Los municipios pusieron todas sus esperanzas en que más industrias se establecieran en sus tierras, pero no todas lograron atraer como hubiesen querido a pesar de utilizar medidas similares, como rebaja de impuestos (lo hizo Girardota pero no logró atraer a más de tres industrias). Las vías de comunicación, la calidad de servicios públicos, la concentración de otros servicios hicieron que el gran centro industrial estuviera protagonizado durante esta primera mitad del siglo XX en Medellín y los tres municipios más próximos, Bello, Envigado e Itagüí. El desarrollo urbano generado a partir de los asentamientos industriales (servicios públicos básicos) aumentó la calidad de vida convirtiéndose en un atractivo para el asentamiento de nuevos pobladores y otras actividades" (Schnitter, 2006).

Medellín cambió su fisonomía durante los primeros treinta años del siglo XX como consecuencia de una conjunción de factores entre los que cuentan, como queda expuesto, la industrialización, el auge de la actividad urbanizadora, la introducción del tranvía que redujo las distancias, y hasta el azar, factor éste que vino a sumarse con la ocurrencia de los incendios de 1918, 1921 y 1926 en la Plaza Berrío, merced a los cuales los primeros edificios de cuatro pisos se integraron al paisaje del primer centro histórico (Melo, 1997).

Durante esos años la ciudad se expandió y sectorizó dramáticamente. Las élites contrataron costosos servicios de profesionales de la arquitectura y la ingeniería para el diseño y la construcción de sus casaquintas, cada vez más al norte, sobre 
las lomas, dando forma a los barrio El Prado y Aránjuez, con abandono de la arquitectura colonial para abrazar una variada y mezclada influencia que mezclaba aportes norteamericanos, europeos y locales, al tiempo que acentuaban la vocación campestre de las tierras de El Poblado que para ese entonces se había beneficiado con el desarrollo de un sistema vial que las comunicaba con Envigado. Años después, en el barrio Aránjuez, con todas las obras de urbanismo que contaba, sería vendido al Distrito para que fuera dedicado a vivienda popular (Archivo histórico) ${ }^{1}$

Además, hicieron su aparición en escena algunas firmas urbanizadoras que promovieron grandes procesos de urbanización, que dieron lugar a barrios como Guayaquil, Los Alcázares y a un tipo de urbanización al filo de la normalidad justificado por la necesidad de extender los beneficios de la tierra a las clases populares, para dar nacimiento a barrios como Campo Valdés, San Germán, Aragón y Castilla, entre otros, de modo que la mancha urbana creció como una gran sombra que llegó a cubrir desde Niquitao al sur, de acuerdo al trazado del valle, esto es, ensanchándose en la parte céntrica y adelgazándose y elongándose en sus desarrollos hacia el nororiente, camino de la parte alta de la ladera oriental, hasta detrás de los Ángeles y arriba de la iglesia de San Miguel, y de las nuevas partes del llano del norte, hacia el Río" (Melo, 1987). Al occidente, además del desarrollo que recibía, bien al norte, el barrio Castilla, día a día se autorizaban nuevas dotaciones de servicios para los corregimientos, llamados también fracciones y en ocasiones barrios, de Belén, La América, Guayabal, hecho que da fe de su progresivo poblamiento. A despecho de lo que sostienen algunos cultores del tema (Bahamón, 2009), para 1938 Otrabanda ya debía acusar algún grado de poblamiento no muy difuso si se considera que los motivos que se hicieron constar en las actas del Concejo Municipal que documentan los antecedentes del acuerdo 142 de 1938, por medio del cual se suprimieron los corregimientos de Belén, América, Guayabal, Robledo y Berlín y se les declaró barrios de Medellín, rezan textualmente:

\section{"esos densos núcleos de población no son ceseríos aislados porque entre sus respectivas cabeceras y el centro de la ciudad hay poca distancia y no existen considerables soluciones de continuidad en lo que a edificaciones se refiere" (Archivo histórico).}

El Valle entero recibía el impacto del desarrollo y del crecimiento, y los cascos urbanos de Itagüí, Envigado y Bello se expandían merced a la oferta laboral que extendían las industrias allí asentadas desde mediados de los años 30, tales como Fabricato en Bello, Textiles Rosellón en Envigado, Sedeco y Tejiunión, Coltejer, Furesa, Delmaíz y Polímeros Colombianos, entre otras, en Itagüí.

Baste un vistazo al panorama global que ofreció el crecimiento demográfico del Valle y del casco urbano de Medellín, para empezar a connotar el rizoma (Moreno,

1 A.H.M., Alcaldía, Junta de Obras Públicas, memoriales, Tomo 265, folios 197-200 transcripción literal del memorial de octubre 15 de 1924 dirigido por Víctor M. Álvarez al Señor Gerente de Obras Públicas Municipales 
2008) que subrepticiamente avanzaba hacia la integración de los cascos urbanos del Valle, bajo el impulso decisivo del polo medellinense:

Cuadro 1. Crecimiento Demográfico Comparado Medellín - Valle De Aburrá 1905-1951

\begin{tabular}{cccc}
\hline Año & Medellín (urbano) & Valle de Aburrá & \% Antioquia \\
\hline 1905 & 31.055 & 105.305 & 15,9 \\
1912 & & 125.407 & 16,9 \\
1918 & 51.951 & 141.797 & 17,2 \\
1928 & 83.955 & 196.612 & 19,4 \\
1938 & 143.952 & 252.124 & 21,2 \\
1951 & 328.294 & 499.756 & 31,8 \\
\hline
\end{tabular}

Tomado de Álvarez, 1996

\section{CONURBACIÓN PROBLEMÁTICA}

Si en los primeros años del siglo XX el proceso de industrialización en recuento se benefició del progresismo que imprimió a su gobierno Rafael Reyes, a partir de los años 30 se vigorizó aún más al amparo de las políticas liberales de Olaya Herrera y López Pumarejo, de modo que a las industrias textilera, cervecera y del vidrio, se sumaron la fabricación de alimentos de consumo masivo, de gaseosas, de cigarrillos a gran escala, de electrodomésticos, para cambiar definitivamente el semblante de la ciudad.

Era preciso, entonces, regular el cauce del progreso, de modo que en el tercer decenio del siglo XX se sentaron las bases normativas de la vida urbana de la ciudad: se expidieron los primeros códigos de tránsito y de urbanización, se estableció el cuerpo de bomberos y se expidió el estatuto de valorización.

Sin embargo, a despecho de este esfuerzo normativo, se aceleró el asentamiento de la clase obrera en la periferia de la ciudad, con ruptura de la marcada tendencia urbana en sentido nororiental en la medida en que extendía sus rutas hasta el costado occidental del río, hacia el corregimiento de La América, cruzado el actual barrio La Floresta, proceso que, sin embargo, no generaba aún subcentros, pues los nuevos desarrollos mantuvieron su dependencia del centro histórico tanto por el sistema vial como por la concentración de las actividades económicas relevantes en ese centro (Montoya, 2011).

A partir de los años 30, la ciudad creció por fuera de los cauces previstos, primero, bajo el impulso de nuevas construcciones para la élite, y luego, con el despliegue de una amplia oferta de vivienda para la población obrera (Ibídem). Prueba de ello se encuentra en el trazado de las rutas que para 1938 servía el tranvía, con destino en 
sitios, la mayoría de los cuales había adquirido o estaba próximo a adquirir condición urbana merced a dicho medio de transporte: Manrique, Aránjuez (extendida hasta Campo Valdés), Robledo, Los Ángeles, Sucre (extendida hasta la plaza Cisneros), El Poblado $^{2}$, Buenos Aires, América y Belén (Correa, 2009). Al margen de esta malla vial, al norte del otro lado del río, empezaban a gestarse los proyectos de San Joaquín, San Germán y Castilla, estos dos últimos, más por la necesidad de los dueños de los terrenos de anticiparse al avance de las invasiones (Coupé, 1993), que por un real interés de adelantar un trabajo de urbanismo controlado y regular.

Desde 1930 y hasta 1951, Medellín creció a una tasa aproximada del 6\% anual que le llevaría a alcanzar en este último año una población de 358.189 habitantes. Los tímidos intentos de regulación urbanística que se habían realizado durante los últimos diez años del siglo XIX y primeros del siglo XX, habían sido rebasados por la práctica y resultaban evidentemente estrechos para encarar las consecuencias de tan súbita explosión de la demografía urbana, que, por demás, afectaba en diversa medida a las principales ciudades intermedias del país.

Para remedio de esta situación, Bogotá y Medellín apelaron a la contratación de los servicios de José Luis Sert y Paul Lester Wiener, a fin de adoptar la técnica de la planificación reguladora, tan en boga a mediados de siglo en el mundo entero, en un esfuerzo por cerrar la brecha creciente entre la normativa urbana y una realidad atizada por los flujos migratorios internos cuyo origen natural residía en el deseo de las gentes del campo de participar de las utilidades del progreso y de la modernidad que capitalizaban las ciudades, pero que en este caso estaba, también, fuertemente influida por la violencia partidista que azotaba más cruelmente y a mansalva a la población campesina.

Bajo la orientación de tan connotados contratistas, se elaboró y adoptó en Medellín el plan piloto o plan regulador de la ciudad, que entre sus aspectos más relevantes, preveía la creación de un cinturón verde alrededor del perímetro de la ciudad, delineaba los elementos estructurales del plan vial, fortalecía el rol cultural del centro histórico de la ciudad, definía la vocación industrial del sur (Melo, 1987), propendía por la zonificación y sectorización de la ciudad, y preveía la necesidad de coordinar una planeación regional que abarcara a todos los municipios del Valle de Aburrá.

Algunos de estos derroteros, sin embargo, trasegaban un camino diferente del que recorrería la ciudad en los años venideros.

El crecimiento continuado de la ciudad a una tasa del 6.1\% anual desde 1951 hasta 1964 generó un gran dinamismo que dio

2 Como dato de interés para el estudio de las relaciones políticas entre Medellín y Envigado, se registra por Correa (2009), que este tramo del tranvía generó inicialmente discrepancias entre los concejos municipales de Medellín y Envigado, que hicieron temer que la ruta sólo podría llegar hasta el límite natural de los dos municipios, que era la quebrada La Zúñiga. 
"como resultado una construcción fragmentada o por partes, respondiendo a los diferentes procesos urbanos, legales o ilegales" (Schniter, 2005),

aceleración de la actividad de la auto construcción informal y sin equipamiento social en las laderas orientales; desproporcionado aumento de la actividad comercial del centro de la ciudad; y descontrolado crecimiento vertical que abrió el paso a rascacielos ajenos al tejido histórico que sobrevivía en torno a la que había sido la plaza principal.

El desmedido crecimiento del comercio en el centro de Medellín y la apertura de la avenida oriental instaron a las familias pudientes que tradicionalmente habían habitado las hermosas quintas del barrio El Prado, expresión de la primera expansión de las élites hacia el Norte de la Plaza Principal, a migrar a laureles, en la margen occidental, y más recientemente hacia las más tranquilas colinas de El Poblado, en el suroriente, que hasta entonces habían oficiado como fincas de recreo, éstas adquirieron un valor y un interés urbanístico acelerado por la construcción de la Avenida Las Vegas, de la variante Las Palmas y de la vía regional hasta la calle 10, que motivó a sus propietarios a lotearlas y ofrecerlas a nuevas firmas de construcción interesadas en darles desarrollo a la manera de conjuntos de vivienda multifamiliar, como finalmente ocurrió a partir de los años 80 (Sanín, 2009).

La realidad desafiaba a los planes porque los códigos socioculturales obedecían a una lógica incompatible con el modelo de desarrollo que la planeación formulaba tanto para el centro, como para las "periferias no desarrolladas" (Echeverría, 2004), se generaron dinámicas incontrolables o informales que no coincidían con la acción institucionalizada pública y privada (Echeverría y Rincón, 2000), si bien diferente de la que operaba en otras ciudades del país, pues el desarrollo descontrolado de la periferias estuvo básicamente a cargo de urbanizadores dueños de las tierras, no de usurpadores y, en no pocos casos, estas urbanizaciones se ajustaban a la normativa existente en materia de retiros, cesiones y áreas libres, de modo que "el problema real y apremiante" era el de los servicios públicos (Coupé, 1993), el equipamiento social y el riesgo generado por la proximidad, al lecho del río o de las quebradas y por la inestabilidad de los terrenos en la ladera.

Pero, como queda dicho atrás, el efecto descrito no debió afectar tan sólo a Medellín. De hecho, demográficamente, entre 1951 y 1974, Bello creció el 173\%, Itagüí el 237\% y Envigado el 114\% (Schniter, 2006), mientras que Medellín creció el 118\% (Álvarez, 1996). Veamos cómo fue el comportamiento estadístico de la demografía y de la ocupación del territorio en los diferentes municipios del Valle desde 1951 hasta 1985: 
Cuadro 2. Crecimiento Demográfico Municipios del Valle 1951-1985

\begin{tabular}{|c|c|c|c|c|c|c|c|}
\hline \multirow{2}{*}{ Municipio } & \multirow{2}{*}{ Fundación } & \multirow{2}{*}{ Creación } & \multicolumn{4}{|c|}{ Población } & \multirow{2}{*}{$\begin{array}{l}\text { Distancia a } \\
\text { Medellín } \\
\text { km }\end{array}$} \\
\hline & & & 1951 & 1964 & 1973 & 1985 & \\
\hline $\begin{array}{l}\text { Medellín } \\
\text { Norte }\end{array}$ & 1616 & 1675 & 385.189 & 772.887 & 1.151 .762 & 1.468 .089 & 0 \\
\hline Bello & 1676 & 1913 & 34.307 & 93.207 & 129.173 & 212.861 & 10 \\
\hline Copacabana & 1615 & 1812 & 10.720 & 19.403 & 29.997 & 40.309 & 16 \\
\hline Girardota & 1620 & 1833 & 10.956 & 12.729 & 17.879 & 23.684 & 26 \\
\hline Barbosa Sur & 1795 & 1812 & 15.507 & 15.242 & 22.271 & 28.623 & 38 \\
\hline Itagüí & 1743 & 1832 & 20.151 & 68.086 & 103.898 & 137.623 & 11 \\
\hline Envigado & 1775 & 1814 & 28.797 & 61.546 & 73.057 & 91.391 & 10 \\
\hline La Estrella & 1685 & 1833 & 8.698 & 16.479 & 23.619 & 29.918 & 16 \\
\hline Sabaneta & 1903 & 1968 & ------* & ------* & 16.518 & 20.491 & 14 \\
\hline Caldas & 1840 & 1848 & 12.431 & 25.081 & 33.630 & 42.158 & 22 \\
\hline $\begin{array}{l}\text { Valle de } \\
\text { Aburrá }\end{array}$ & & & 526.756 & 1.084 .660 & 1.601 .804 & 2.095 .147 & \\
\hline $\begin{array}{c}\text { Área } \\
\text { Metropolitana }\end{array}$ & & & 497.959 & 1.023 .114 & 1.528 .747 & 2.003 .756 & \\
\hline
\end{tabular}

Cuadro con fuente DANE- AMAV, tomado del documento La ocupación del territorio en el proceso de urbanización del área metropolitana del Valle de Aburrá, Colombia, autoría de Schnitter Patricia, Giraldo Marta Lía, y Patiño Juan Manuel, publicado en scripta nova, revista electrónica de Geografía y Ciencias Sociales de la Universidad de Barcelona, Vol. X, No. 218 (83), 1 de agosto 2006

Estas dinámicas tuvieron un giro dramático a partir de mediados de los años 60 habida cuenta que el proceso de industrialización se desaceleró más rápidamente en esta región que en el resto del país, en parte por las mismas causas que otrora la llevaron a su auge: la quiebra de la estrecha relación que hubo entre las élites económicas y políticas (Gouëset, 1998), la ineficiencia y dependencia económica interna y externa que causó el monopolio del café, la ineficiencia que en materia de competitividad en los mercados nacionales e internacionales causa el proteccionismo estatal, y la fragilidad del sector industrial limitado a la producción de bienes de consumo (Arango, 1998).

Esto explica, por lo menos parcialmente, la disminución que experimentó la tasa de crecimiento poblacional urbana en los más grandes receptores de migración del valle de Aburrá entre 1964 y 1973 en comparación con lo que había ocurrido en el periodo 1951 1964. Medellín creció tan sólo el 49.19\% (Álvarez, 1996), Itagüí el 53\%, Bello el 38,6\%, y Envigado, el 19\% (Schnitter, 2006).

Los nuevos inmigrantes no fueron ya, por supuesto, recibidos por la gran industria del estilo fordista periférico que dominó hasta inicios de los años 70 (Betancur, et al., 
01), sino por el sector de la construcción, dinamizado como fue a partir de la puesta en marcha del plan de las cuatro estrategias, y por un nuevo mercado de trabajo que se hizo fuerte a partir de mediados de los 80 , basado en la maquila de las confecciones a través de una gran red de micro y fami-empresarios, con fines de exportación. Huelga advertir que se trató de una oferta laboral de bajo perfil, inestable, en el caso de la construcción, informal, en el caso de las confecciones para terceros, y en uno y otro caso, altamente proclives a la marginalidad que no a la inclusión social.

La interrelación existente entre esta crisis industrial y la ocupación del territorio se reflejó en la redefinición de la localización y en la reconversión (Giraldo, 2008) de la industria. Ya desde los años 40, los trabajos de canalización del río al sur del valle, habilitaron los terrenos adyacentes para el asentamiento de la industria en los municipios de Itagüí y Envigado, especialmente y crearon una tendencia que vino a consolidarse con la crisis de la gran industria, parte de la cual se radicó allí, al tiempo que otras empresas se trasladaron al oriente antioqueño, en especial hacia Rionegro, en procura de menores costos asociados a la producción (Betancur, et al, 01).

Nada de esto impidió que los cascos urbanos de los más grandes municipios asentados en el Valle crecieron en dirección a todos los puntos cardinales con una dinámica policéntrica, de la mano de las urbanizaciones que levantaban, tanto los constructores privados alimentados con el flujo del nuevo crédito upaquizado, como el Instituto de Crédito Territorial y el banco Central Hipotecario, en ejecución de grandes programas estatales de vivienda para los sectores populares, con una dinámica que produjo, finalmente, la conjunción de los núcleos citadinos de los municipios de Medellín, Bello, Envigado e Itagüí.

El sector público institucional también se reconfiguró a partir de los años 70 . De una parte, experimentó un complejo proceso de fortalecimiento ejemplarizado con la reorientación del accionar de Valorización en dirección a la implementación del Plan Vial, y a la transformación de la ciudad, especialmente en el centro y en las comunas 4 y 6; así como con el robustecimiento de la Secretaría de Obras Públicas, que emprendió un ambicioso plan de "habilitación de barrios" con el propósito de promover la extensión progresiva de la red de servicios públicos domiciliarios, acercándolos a los habitantes de los asentamientos subnormales (Coupé, 1993).

\section{LA METROPOLIZACIÓN INSTITUCIONALIZADA}

La tendencia del valle de Aburrá a configurarse como una unidad articulada de desarrollo se hizo realidad por la fuerza de los hechos por causa de la consolidación del proceso de conurbación y de la creación de centralidades urbanas en red a lo largo del cauce de su principal elemento estructurante: el río. Lo habían advertido en la década del 50, desde la perspectiva de la planeación del desarrollo José Luis Sert y Paul Lester Wiener; lo habían anticipado con su accionar las Empresas Públicas de 
Medellín en los últimos decenios, y lo señalaron como una necesidad, desde finales de los años 60, la administración de Medellín y la gobernación de Antioquia, en particular desde la perspectiva de los requerimientos de la movilidad y del transporte masivo y rápido de pasajeros entre los centros urbanos del valle de Aburrá.

La idea de satisfacer esa necesidad mediante la construcción de un Metro que cubriera a lo largo el Valle, fue auscultada y desestimada por el primer Gerente de la primera empresa oficial creada para ese fin a mediados de los 60 , fundamentalmente porque ni los altos costos asociados al proyecto, ni la topografía quebrada, ni las altas concentraciones de población en las laderas, lo hacían aconsejable. La idea revivió, sin embargo, hacia 1979, con la creación, por asociación del Municipio de Medellín y el Departamento de Antioquia, de la Empresa de Transporte Masivo del Valle de Aburrá (Alvear, 1990) con el fin de construir, administrar y operar el sistema de transporte masivo para generar desarrollo y buscar ofrecer Calidad de Vida a todos los habitantes del Valle de Aburrá.

Independientemente de las consideraciones que puedan hacerse sobre la viabilidad económica del Metro, la visión metropolitana del asunto era perfectamente válida, y para los primeros años de la década del 70 el aumento de la población, el crecimiento urbano y los requerimientos de lo movilidad dentro del valle de Aburrá lo ratificaron.

Fue esa la perspectiva que se impuso en los trabajos antecedentes del Plan Vial Metropolitano para Medellín 1969 - 1970, y que se materializó por parte de la Gobernación de Antioquia al crear una dependencia encargada de proyectar un plan metropolitano (Schnitter, 06) en un sentido promotor de la articulación del accionar, hasta entonces, independiente y no siempre coincidente de los órganos de administración de las distintas localidades inmersas, sin embargo, en un resultado de conurbación pleno, que obligaba a pensar en clave metropolitana las necesidades relacionadas con la provisión de medios de consumo o de equipamiento colectivo equilibrado entre municipios cuyos desarrollos urbanos periféricos se estorbaban y cuyos habitantes vivían una movilidad cruzada cada vez más intensa.

Esta perspectiva asociacionista observada por la élite política antioqueña y medellinense se constituyó en un antecedente importante que contribuye a explicar la expedición en el orden nacional del decreto 3104 de 1979 por medio del cual se introdujo la institución del Área Metropolitana en el derecho público colombiano y se autorizó la creación de las primeras Áreas Metropolitanas en Colombia.

Con apoyo en esa normativa la Asamblea departamental de Antioquia expidió la Ordenanza No. 34 de Noviembre 20 de 1980, por medio de la cual se dispuso la entrada en funcionamiento del Área Metropolitana del Valle de Aburrá (AMVA), la pionera entre ellas en Colombia, integrada inicialmente por Medellín, Bello, Barbosa, Copacabana, La Estrella, Girardota, Itagüí, Envigado, Caldas y Sabaneta, y de la cual sólo se sustrajo con el tiempo el municipio de Envigado. 
La misión del Área Metropolitana del Valle de Aburrá se orientó, bajo la vigencia del decreto 3104 de 1979 hacia la programación y coordinación del desarrollo armónico e integrado del territorio del Valle y hacia la racionalización de la prestación de los servicios públicos a cargo Medellín y de los otros ocho (8) municipios que la conforman. Para el efecto, adoptó mediante Acuerdo 012 de noviembre 6 de 1985, el Plan de desarrollo metropolitano del valle de Aburrá, para la consolidación de la metrópoli; y entre 1986 y 1990 aprobó el plan vial metropolitano y los planes de ordenamiento territorial Norte y Sur, e inició las gestiones conducentes a la concertación con los municipios miembros, de los planes de ordenamiento territorial de las respectivas municipalidades (AMVA, 07).

La urgencia que demandaba la temática del ordenamiento territorial contrastaba, ciertamente, con la relativa serenidad con la que podía abordarse el tema de los servicios públicos como quiera que la empresa EPM prestaba servicios a los diferentes municipios del Valle desde antes de la consolidación del proceso de conurbación (Varela, 2010).

Ya en vigencia de la ley 128 de 1994, y dentro del nuevo marco funcional que allí se le confirió a la institución, se creó la Dirección de Planeación del Área Metropolitana de Medellín, y se dio inicio a una cadena de ejercicios de planeación estratégica de perspectiva metropolitana, que fungen como antecedentes del plan estratégico de Medellín Proyecto Metrópoli 2002 - 2020, a partir del cual se puede visualizar el desarrollo futuro de Medellín, del Área Metropolitana y de la Región.

Al lado de este discurrir institucional, los municipios crecían (ver figura) y generaban asimetrías, segregación socio espacial y rupturas de la trama urbana, fenómenos en los que incidía de manera especial la irrupción acelerada de las urbanizaciones cerradas y la realización de grandes proyectos de infraestructura sin consideración por la continuidad del territorio; al tiempo que el crecimiento de la mancha urbana asentada en el valle generaba una "dicotomía norte-sur" y fragmentación a modo de ciudades satelitales" signadas por la marginalidad social, la violencia, la inseguridad y el miedo (CEHAP, 98) en medio de la expansión social de una economía subterránea fuertemente determinada por el Narcotráfico, de la guerra del Estado contra este negocio ilícito, de la conformación de milicias para la defensa del negocio y de la incursión del proyecto militar urbano por parte de las guerrillas. 
Figura 1. Superposición Gráficos Ocupación Compacta del Valle 1948-1970

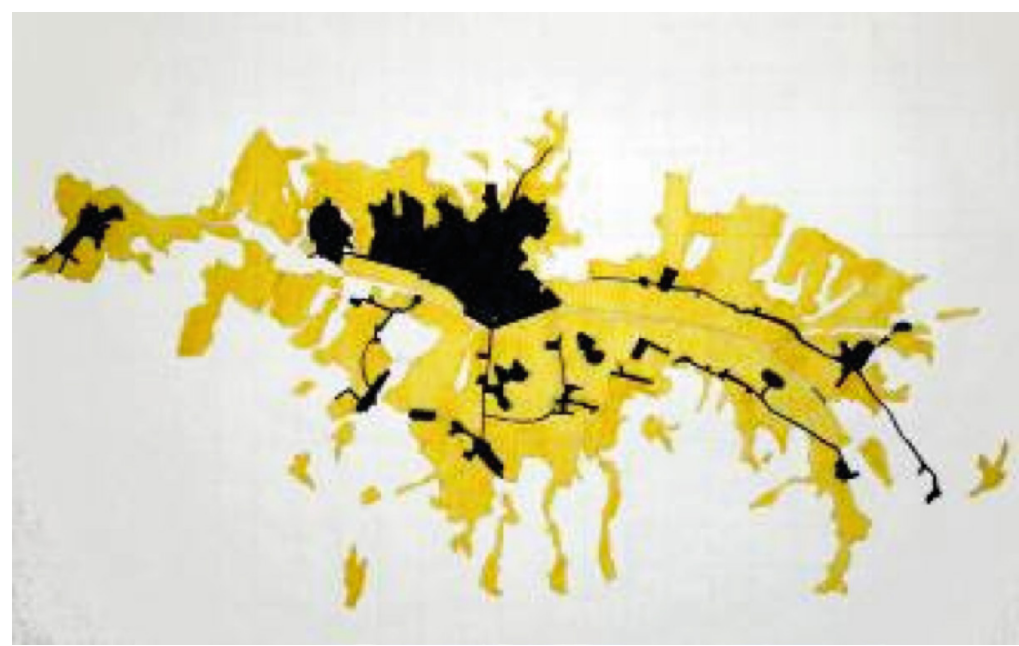

Fuente: Schniter, Patricia

Figura que registra en negro la ocupación compacta del plano del Valle de 1948 y en amarillo la ocupación de 1970, tomada de Schniter, Patricia, Construcción fragmentaria, característica del crecimiento metropolitano de la ciudad de Medellín, Colombia: lectura cartográfica de tres momentos significativos. En Scripta Nova, revista electrónica de geografía y ciencias sociales, Universidad de Barcelona, Vol. IX, No.. 194 (103), 1 de agosto de 2005.

Medellín, municipio núcleo del Área Metropolitana, pasó de tener 1.834.881 habitantes en 1993, a 2.159.243 en el año 2000, y cinco años después contaba ya 2`499,080 personas, equivalentes al 67\% del total de la población metropolitana que registraba en ese mismo año 3.729 .970 vecinos (POT, 2006).

La altísima densificación poblacional en algunos de los municipios del Área Metropolitana, la concentración por sobre el $80 \%$ de las poblaciones del Valle en los cascos urbanos, excepción hecha de Barbosa (ver Cuadro 3), y el entrelazamiento de los desarrollos urbanos periféricos de los municipios de Medellín, Envigado, Itagüí, la Estrella y Sabaneta, al Sur del Área metropolitana (Jiménez, 09), activaron las alarmas acerca de las asimetrías existentes en relación con la oferta de uso de suelo disponible en el Área, así como sobre la creciente dificultad que tenían las autoridades para promover el acceso de todos los ciudadanos, empresas y de la comunidad del Valle, en general, a la multiplicidad de servicios, equipamientos y oportunidades que ofrecía la región, que es el sentido que en ese contexto se ha dado a la movilidad (AMVA, 2009). 
Cuadro 3. Densidades Poblacionales Municipios del Valle

1995

\begin{tabular}{cccccc}
\hline MUNCIPIOS & $\begin{array}{c}\text { ÁREA } \\
\text { KM }\end{array}$ & POBLACIÓN & $\begin{array}{c}\text { DENS. } \\
\text { HAB/KM }\end{array}$ & $\begin{array}{c}\text { POBL. } \\
\text { URBANA }\end{array}$ & $\begin{array}{c}\text { POBL. } \\
\text { RURAL }\end{array}$ \\
\hline BARBOSA & 206 & 43.725 & 212 & $42.70 \%$ & $57,35 \%$ \\
BELLO & 149 & 311.544 & 2.091 & $97.40 \%$ & $2.60 \%$ \\
CALDAS & 150 & 56426 & 376 & $91.22 \%$ & $8.78 \%$ \\
COPACABANA & 170 & 54046 & 772 & $85.10 \%$ & $14.90 \%$ \\
ENVIGADO & 50 & 135.042 & 2701 & $95.41 \%$ & $4.59 \%$ \\
GIRARDOTA & 78 & 32.649 & 419 & $81.80 \%$ & $18.20 \%$ \\
ITAGÜÍ & 17 & 202617 & 11.919 & $97.23 \%$ & $2.77 \%$ \\
LA ESTRELLA & 35 & 38869 & 1.139 & $82.96 \%$ & $17.04 \%$ \\
MEDELLÍN & 382 & 1.858 .685 & 4866 & $95.04 \%$ & $4.96 \%$ \\
SABANETA & 15 & 31 & 2 & $82.81 \%$ & $17.19 \%$ \\
\hline
\end{tabular}

Fuente: Anuario Estadístico Metropolitano 1995. Cuadro tomado de Centro de estudios del hábitat popular CEHAP, Vivienda y hábitat claves en el tejido de las ciudades facultad de Arquitectura, Universidad Nacional de Colombia, Plan estratégico de Medellín y el Área Metropolitana, Naciones Unidas - Proyecto de Gestión Pública, Medellín, 1998.

En estas circunstancias, los nuevos inmigrantes y las nuevas generaciones de los pobladores de escasos recursos se ven compelidos a ocupar tierras allende los contornos que la planificación señalaba para las áreas de futura expansión, dieron origen a barrios como La Avanzada, Carpinelo, María Cano-Carambolas, Aldea Pablo Sexto, Compromiso, El Chispero, El Chamizo, La Cruz y Bello Oriente, con ocupación creciente de las escarpas nororiental y noroccidental, que superaron de facto y forzaron la modificación del perímetro sanitario y urbano municipal de manera reactiva, lo que se explica, en alguna medida por la dependencia que tiene el perímetro urbano oficial de la cota de servicios, y en últimas, de las proyecciones de expansión de sus redes por parte de EPM, entidad que se comporta monopólicamente en el área y en el sector de los servicios públicos (Bahamón, 2009).

En lo que respecta al otro factor determinante del perímetro urbano, que es la infraestructura vial, su análisis debe considerar todas sus dimensiones, tanto las estrictamente intra-municipales, como en las supra-municipales, metropolitanas y regionales, y su capacidad de articulación con al resto del país. No son pocos los esfuerzos que se han desplegado en el propósito de aproximar a los habitantes de los distintos municipios del Valle a la oferta de servicios a través de una malla de transporte público. De hecho, este sistema de intercomunicación terrestre ha contado, desde 1995 con el aporte del Metro primero, con la puesta en funcionamiento de 
las líneas "A" y "B", la primera, en el tramo entre las estaciones Niquía y Poblado, extendido más tarde hasta Itagüí y proyectada hasta el municipio La Estrella, y la segunda, extendida en dirección al Occidente de la ciudad, a través de Suramericana y la Floresta, hasta San Javier, e interconectando, desde allí, en sentido sur-norte, con la línea "J", en la modalidad Metrocable, para atención de la zona Centro y Noroccidental, pasando por Juan XXIII, y Villajuelos hasta llegar a La Aurora. A estas líneas se agregó la nueva línea turística Santo Domingo-Arví (Corregimiento de Santa Helena), por cable aéreo, de la que se benefician todos los habitantes del Valle de Aburrá y de sus municipios cercanos ${ }^{3}$.

El Metro, que cuenta hoy con 32 estaciones, se articula con un prolífico sistema de transporte multimodal que ha optimizado la comunicación terrestre del valle de Aburrá con Bogotá y la Costa Atlántica, que ha mejorado la comunicación internacional vía aérea $\mathrm{y}$, en general, ha introducido equipamientos necesarios para adecuar el espacio a los requerimientos del sistema productivo (Franco, 2006). Su núcleo lo constituye el corredor multimodal de transporte del río Medellín (río Aburrá), que se complementa con ejes viales longitudinales en dirección nortesur y oriente-occidente, y un generoso sistema vial metropolitano que permite la conexión de Medellín con los diferentes municipios del Valle. Entre sus elementos se encuentran: a) la Autopista Norte - Avenida del Ferrocarril - Avenida Guayabal, que comunica a Bello, Medellín e Itagüí, b) la Avenida Los Industriales - Avenida Las Vegas, que conecta la ciudad con los municipios del suroriente del valle de Aburrá, c) la Avenida El Poblado, como otro corredor de conexión con la zona sur del valle, d) la Avenida 80-81, que se extiende desde el sur de Medellín hasta el municipio de Bello, d) la Carrera 65, que cruza los municipios de Bello y Medellín, e) la Conexión entre La Estrella, San Antonio de Prado, Itagüí, Belén-Rincón, carrera 76, Castilla y Bello, y f) la Vía Machado - Vía Moravia Acevedo, que conecta la ciudad con los municipios de Bello y Copacabana. En el 2006 se proyectaban, en adición a estos, los siguientes: a) Longitudinal Occidental (Circunvalar Occidental), como un proyecto de conexión metropolitana entre los municipios del norte y del sur, con atravesamiento periférico por Medellín; b) Longitudinal Oriental (Circunvalar Oriental), como un proyecto de conexión metropolitana entre los municipios del norte y del sur, con atravesamiento periférico por Medellín (POT, 06) ${ }^{4}$ (Ver Cuadro).

Todo este sistema se articula, finalmente en una red de terminales integrada por el aeropuerto internacional José María Córdova en el Municipio de Rionegro, el aeropuerto Olaya Herrera; la Terminal Norte de transporte intermunicipal y nacional; la Terminal Sur de transporte intermunicipal y nacional, las Estaciones del Metro Línea A, y f) y las Estaciones de Metroplús del Sistema Sur (ibídem).

3 Recuperado de www.metrodemedellin.gov.co/index.php?... -

4 (POT 06) 
Ahora bien, no toda la inversión pública se ha centrado en torno a la infraestructura de transporte. El Municipio de Medellín ha emprendido un plan de intervención sobre las comunas informales 1 y 2 del sector nororiental, y ha generado allí $125.000 \mathrm{~m}^{2}$ de espacio público, con 18 nuevos parques y construcción de senderos y puentes peatonales, obras de estabilización de terrenos y, en general, con adecuación de nuevos equipamientos colectivos, con inversiones que superan hasta en cuatro veces las realizadas en la construcción del Metrocable (Montoya, ib).

\section{PRESENTE Y FUTURO DEL VALLE EN PERSPECTIVA REGIONAL}

El cuadro circunstancial hasta aquí descrito pone en relieve la necesidad imperiosa de adelantar un esfuerzo mancomunado de los municipios del Área Metropolitana para saldar la gran deuda social que se ha incubado a lo largo del siglo XX, para crear un equilibrio hasta ahora inexistente en el equipamiento colectivo, y para articular los planes de ordenamiento territorial. En ese sentido se han movido los trabajos que desde el 2004 se han adelantado por el municipio, en especial, por el de Medellín, y ese ha sido el espíritu que ha inspirado la realización, bajo el liderazgo del Área metropolitana, con participación de los municipios que la integran y de Envigado, y con el acompañamiento del Ministerio de Ambiente Vivienda y Desarrollo Territorial, entre otras instituciones del orden nacional, del macro evento que se denominó "Taller de Ordenamiento Territorial integrado", cuyo resultado parcial y provisional ha sido la suscripción de un pacto denominado directrices metropolitanas de ordenamiento territorial, hacia una Región de Ciudades, sancionado como Acuerdo Metropolitano No. 15 de septiembre de 2006, en el que se define un modelo territorial integrado para todos los municipios del valle que obrará como elemento articulador de los diferentes Planes de Ordenamiento Territorial (Pérez, 2006).

Bajo estas directrices y con el desarrollo de los Planes Estratégicos del Aburrá Norte y Sur, de Movilidad Metropolitana, del Plan Regional de Gestión Integral de Residuos Sólidos, del Plan Maestro de Zonas Verdes Urbanas, y del Plan Maestro de Seguridad, Defensa y Justicia, entre otros, se ha avanzado camino de la articulación del desarrollo metropolitano equilibrado en sus diferentes frentes, al tiempo que se han propiciado las condiciones para que los municipios realicen intervención de sus territorios con el fin de estrechar la brecha de la deuda social (Pérez, Ibídem).

Hoy, el Valle de Aburrá conforma una realidad metropolitana estrechamente comunicada con el centro del departamento, e íntimamente integrada al oriente cercano. Se desenvuelve en el medio de nueve subregiones de Antioquia, y de departamentos circunvecinos con inmensos potenciales, grandes inequidades, altos márgenes de violencia y "profundas interdependencias con Medellín”. Recoge fácilmente el $70 \%$ de la población, del poder, de la riqueza, de la cultura, pero 
también de la pobreza y de la marginalidad de Antioquia. La integración real de los valles de San Jerónimo (sobre el que se asientan Santa Fe de Antioquia, Sopetrán y San Jerónimo), de San Nicolás (que recoge a Río Negro, Marinilla, Guarne, La Ceja y El Retiro) y de Aburrá, es un hecho cuyos indicadores pasan por las obras de infraestructura, como el túnel de occidente y la doble calzada al aeropuerto José María Córdova, tanto como por las dinámicas territoriales de la inversión privada, como se evidencia con el desplazamiento industrial y residencial camino del oriente antioqueño, y como se impone hacia el futuro por la conveniencia de dar salida a la producción industrial por el puerto de Urabá (Pérez, ib).

\section{REFERENCIAS}

Acosta de Samper, Soledad. Gaspar de Rodas, Colonizador de Antioquia, en Biografías de hombres ilustres o notables, relativas a la época del descubrimiento, conquista y colonización de la parte de América denominada actualmente EE UU. de Colombia, Bogotá, Imprenta de la luz, 1883. Colección de documentos en la Biblioteca Virtual de la Biblioteca Luis Ángel Arango del Banco de la República

Álvarez, Víctor M. "Poblamiento y población en el Valle de Aburrá y Medellín, 1541 - 1951". Jorge Orlando Melo (Editor) Historia de Medellín. Suramericana de Seguros, Bogotá. 1996.

Alvear Sanín José. El negocio del metro: Experiencias para Bogotá, Señal Editora, Medellín, 1990.

Arango Jaramillo, Mario. Los funerales de Antioquia la Grande: la bancarrota del modelo económico antioqueño Medellín, Ed. J. M. Arango, 1990.

Archivo Histórico de Medellín, transcripción textual de documentos, consultado en biblioteca-virtual-antioquia-udea.edu.co/pdf/49/49-1037251204.pdf el 20 de julio de 2011.

Área Metropolitana del valle de Aburrá, Patiño Marín Juan Manuel, Subdirección de Planeación, La gestión del territorio Metropolitano. Medellín, 2007. Recuperado de www.medellin.gov.co/.../PRESENTACION\%20Area\% 20Metropolitana.pdf

Bahamón Alvarez Gabriel. Análisis del proceso de delimitación de espacialidades urbanas, un caso de estudio en Medellín. Facultad de Arquitectura, Universidad Nacional, 2009

Betancur, María Soledad, Urán Arenas, Omar, Stienen, Ángela. Cadenas Productivas y redes de acción colectiva en Medellín y el Valle de Aburrá, en Economía Sociedad y Territorio, Vol. III, núm. 102001.

Botero Gómez Fabio. Cien años de vida de Medellín, Universidad de Antioquia, Medellín, 2000. Citado por Santiago Correa en Urbanismo y Transporte. El tranvía de Medellín. 1919- 1950. Consultado en portal.uexternado.edu.co, 2009 
Centro de estudios del hábitat popular CEHAP, Vivienda y hábitat. Claves en el tejido de las ciudades facultad de Arquitectura, Universidad nacional de Colombia, Plan estratégico de Medellín y el Área metropolitana, Naciones Unidas Proyecto de Gestión Pública, Medellín, 1998.

Corantioquia, Universidad de Antioquia, Determinantes socioeconómicas y físico espaciales para el ordenamiento ambiental territorial, Medellín, 2006, documento Recuperado de: http://www.corantioquia.gov.co/docs/PGAR/ ANALISIS/pdfs/2.\%20\%20POBLAMIENTO $\% 20$ HISTORICO.pdf

Correa Restrepo, Juan Santiago. Minería y poblamiento en Antioquia, Siglos XVII Y XVIII, 2008. Recuperado de: http://repository.cesa.edu.co/bitstream/10726/ 113/1/6\%20J.Correa-mineria\%20y\%20Poblamiento.pdf

Correa, Juan Santiago, Urbanismo y transporte: El tranvía de Medellín (1919 1950) en portal.uexternado.edu.co, 2009

Coupé, Francoise, "las urbanizaciones piratas en Medellín: El caso de la familia Cock - Medellín: Centro de estudios del hábitat popular, Universidad Nacional de Colombia, 1993.

Echeverría R. María Clara y Rincón Patiño Análida. Ciudad de Territorialidades. Polémicas de Medellín. Serie Investigaciones No. 22, CEHAP, Universidad nacional de Colombia, Sede Medellín, Convenio con Colciencias, Medellín, 2000, 211 p.

Echeverría Ramírez, María Clara, Por una mirada abierta de la ciudad. Tensiones entre lo local y lo global. Universidad Nacional de Colombia. Sede Medellín, 2004. En biblioteca. Universia.net/.../mirada-abierta.../52503312.html -)

Enciclopedia Microsoft ${ }^{\circledR}$ Encarta ${ }^{\circledR}$ Online 2009. “Colombia”. http://es.encarta.msn. com 1997-2009 Microsoft Corporation

Escobar Villegas, Juan Camilo. La historia de Antioquia, entre lo real y lo imaginario. Un acercamiento a la versión de las élites intelectuales del siglo XIX. Revista Universidad EAFIT, abril- junio, 51-79.

Franco Restrepo Vilma Liliana, Poder regional y proyecto hegemónico: el caso de la ciudad metropolitana de Medellín y su entorno regional 1970 2000. Instituto Popular de Capacitación, Medellín, Antioquia, 2006.

García Julio César, Medellín, Revista repertorio histórico, de la Academia Antioqueña de Historia, Vol. 38, No 251, 1988)

Giraldo Romero, Marcela. La reconversión de las áreas industriales en el corredor del río Aburrá. Consultado en institutodeestudiosurbanos.com/index. php?option $=$ com...task...

González Escobar, Luis Fernando. Del higienismo al taylorismo: de los modelos a la realidad urbanística de Medellín, Colombia, 1870-1932. Revista Bitácora Urbano territorial, enero-diciembre, año Vol. 1, núm. 011 Universidad Nacional de Colombia, Bogotá, 2007. 
Gouëset, Vincent. Bogotá, nacimiento de una metrópoli; la originalidad del proceso de concentración urbana en Colombia en el siglo XX. Bogotá, Tercer mundo editores, 1998.

Jiménez Rodríguez, Andrea. Movilidad y Centralidades un diálogo urbano. Universidad Nacional de Colombia, facultad de Arquitectura, Escuela de Planeación Urbano regional, 2009.

Londoño Pardo, Horacio. Los fundadores y fundaciones de Medellín, según el derrotero de Julio César García. En repertorio histórico, de la Academia antioqueña de historia, octubre de 1965, Vol. 21 No. 196.

Medina Restrepo, Martín Alfonso. Historia de la independencia del Departamento de Antioquia, 1810-1816. Medellín, Universo, 1984. Citado por Carlos Andrés Orozco Guarín, en Archivo histórico de Medellín, programa de memoria y patrimonio, Subsecretaría de Cultura, Medellín, 2006. Recuperado de http://www. reddebibliotecas.org.co/sites/Bibliotecas/Cultura/Documents/ Historia\%20Institucional $\% 20 \mathrm{de} \% 201 \mathrm{a} \% 20 \mathrm{Alcald} \% \mathrm{C} 3 \% \mathrm{ADa} \% 20 \mathrm{de} \% 20$ Medell\%C3\%ADn\%201800-1860.pdf

Melo Jorge Orlando, La conquista de Antioquia 1500 - 1580, publicado en Melo, Jorge Orlando, Historia de Antioquia, Medellín, Suramericana de Seguros, 1987, y recuperado en Internet en http://www.jorgeorlandomelo.com/conquista_de_ antioquia.htm

Melo, Jorge Orlando. Espacio e Historia en Medellín. Medellín, 1997. Consultado en www.jorgeorlandomelo.com/espaciomedellin.htm -

Molina, Luis Fernando, Publicación digital en la página Web de la Biblioteca Luis Ángel Arango del Banco de la República. http://www.banrepcultural.org/ blaavirtual/biografías/berrpedr.htm. Búsqueda realizada el 20 de julio de 2011

Montoya, Catalina, Presentación Transformación de la marginalidad según modelos de intervención: Medellín - Sector Nororiental 1990-2007 (Comunas 1 y 2) en el III curso taller de recomposición urbanística de la ciudad informal. Puerto Príncipe, Haití, 26 de febrero de 2011. Recuperado de http://www.inur.es/ materiales/presentaciones_iii_taller/montoya_comuna_nororiental.pdf y consultada el 26 de julio de 2011.

Moreno Jaramillo, Cecilia Inés. La conurbación: rizoma humano y hecho ambiental complejo. VII Seminario Nacional de Investigación Urbano Regional: Diversidad y desigualdad en territorios contemporáneos. Universidad Nacional de Colombia, Sede Medellín, 2008. Recuperado en www.bdigital.unal.edu. co/3363/ 1/CIM-CONURBACION.pdf.

Palacios, Marco. (1999). Parábola del liberalismo. Editorial, Norma, Bogotá.

Pérez Jaramillo, Jorge. HACIA UNA REGIÓN DE CIUDADES. En publicación: Desde la Región, No. 47. Tema: Medellín. Más allá de sí misma. Corporación Región: Colombia. Diciembre. 2006. Recuperado de http://www.region.org.co/ elem_prov/pdf/desde-la-region/Desde-la-Region-47.pdf 
Perfetti, Verónica. "Tres proyectos para un deseo: la ilusión de una ciudad”. Jorge Orlando Melo (Editor) Historia de Medellín, Tomo I y II, Medellín, Suramericana de Seguros, 1996.

Rendón Cuartas, Gloria. División Territorial y administrativa para Antioquia durante el siglo XIX, archivo histórico de Antioquia, Dirección de Cultura, Secretaría de Educación y Cultura de Antioquia, 1997. Citado por Carlos Andrés Orozco Guarín, en Archivo histórico de Medellín, programa de memoria y patrimonio, Subsecretaría de Cultura, Medellín, 2006. Recuperado de http://www. reddebibliotecas.org.co/sites/Bibliotecas/Cultura/Documents/ Historia\%20Institucional $\% 20 \mathrm{de} \% 201 \mathrm{a} \% 20 \mathrm{Alcald} \% \mathrm{C} 3 \% \mathrm{ADa} \% 20 \mathrm{de} \% 20$ Medell\%C3\%ADn\%201800-1860.pdf

Restrepo Uribe, Jorge. Medellín, su origen, progreso y Desarrollo. Servigráficas, Medellín, 1981.

Robledo, Emilio. El mariscal Jorge Robledo. Bogotá, ABC, 1945.

Sanín Naranjo, Paula. ¿De ciudad abierta a ciudad cerrada? Configuraciones Socio Espaciales en el barrio El Poblado, Medellín. Territorios, No. 23, 2010 pp. 123 -142 Universidad del Rosario, Bogotá.

Schniter, Patricia, Construcción fragmentaria, característica del crecimiento metropolitano de la ciudad de Medellín, Colombia: lectura cartográfica de tres momentos significativos. En Scripta Nova, revista electrónica de geografía y ciencias sociales, Universidad de Barcelona, Vol. IX, núm. 194 (103), 1 de agosto de 2005

Schnitter,Patricia Martha Lía Giraldo, Juan Manuel Patiño, La ocupación del territorio en el proceso de urbanización del área metropolitana del Valle de Aburrá, Colombia, en Scripta Nova, revista electrónica de geografía y ciencias sociales, Universidad de Barcelona. Vol. X, No.. 218 (83), 1 de agosto de 2006

Segundo Foro Metropolitano: Ocupación territorial Metropolitana. Ponencia AMVA, Directrices Metropolitanas de Ordenamiento Territorial para el Valle de Aburrá: Hacia una Región de ciudades. Patiño Marín Juan Manuel, Pereira, 2009.

Twinam, Ann. Mineros, comerciantes y labradores: las raíces del espíritu empresarial en Antioquia, 1763-1810), Medellín FAES, 1985

www.medellín.gov.co. Acuerdo 046 de 2006, Plan de Ordenamiento Territorial, 2006.

www.metrodemedellin.gov.co/index.php?... - En caché

www.metropol.gov.co/ - En caché 


\section{APÉNDICE ILUSTRATIVO}

Figura 1. Medellín, 1791. Tomado de Concejo de Medellín y www.vistaz.com en Bahamón, 2009

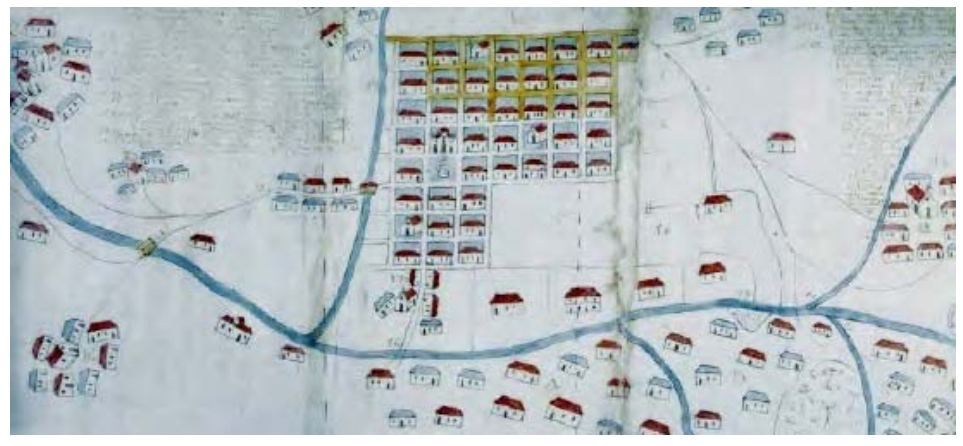

Figura 2. Medellín, 1889. Escuela de Minas. Tomado de Galería de Imágenes. Fichero 41/45 Escuela de hábitat CEHAP Facultad de Arquitectura en http://agora.unalmed.edu.co/galeria/ displayimage.php?album $=77 \&$ pos $=40$

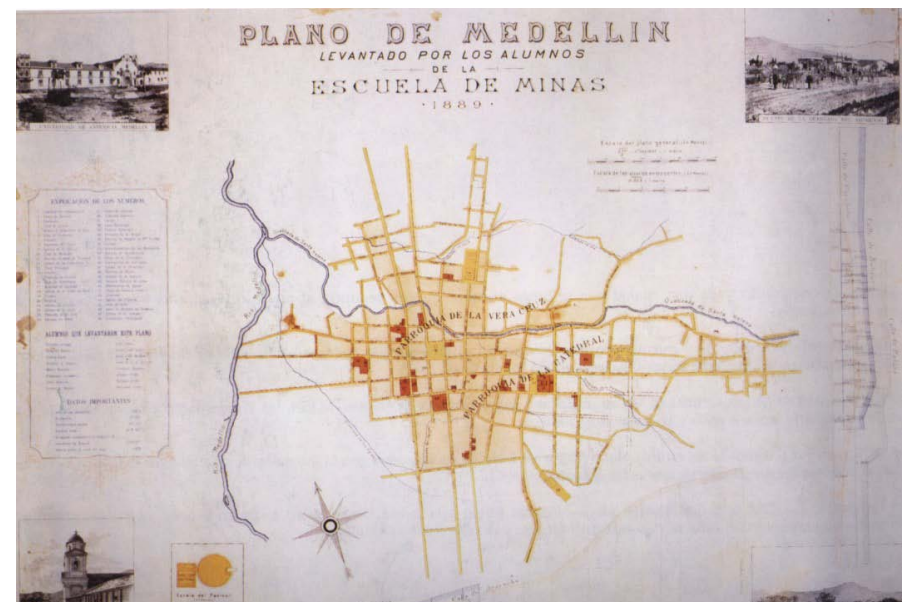


Figura 3. Plano ciudad de Medellín, 1908 S. Pearson \& Son Limited. Tomado de Galería de Imágenes. Fichero 42/45 Escuela de hábitat CEHAP Facultad de Arquitectura en http:// agora.unalmed.edu.co/galeria/displayimage.php?album $=77 \&$ pos $=40$

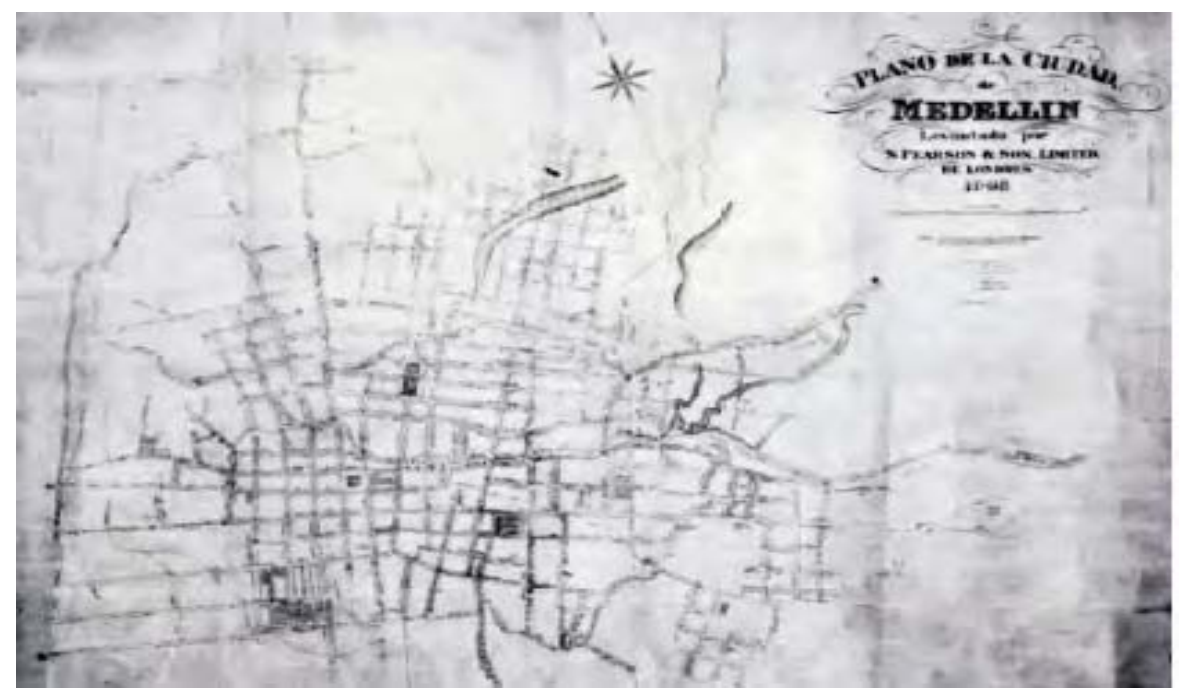

Figura 4. Plano Medellín, 1923. Pearson.

Tomado de http://www.viztaz. com.co/usvm/botones/mapas/1923.jpg

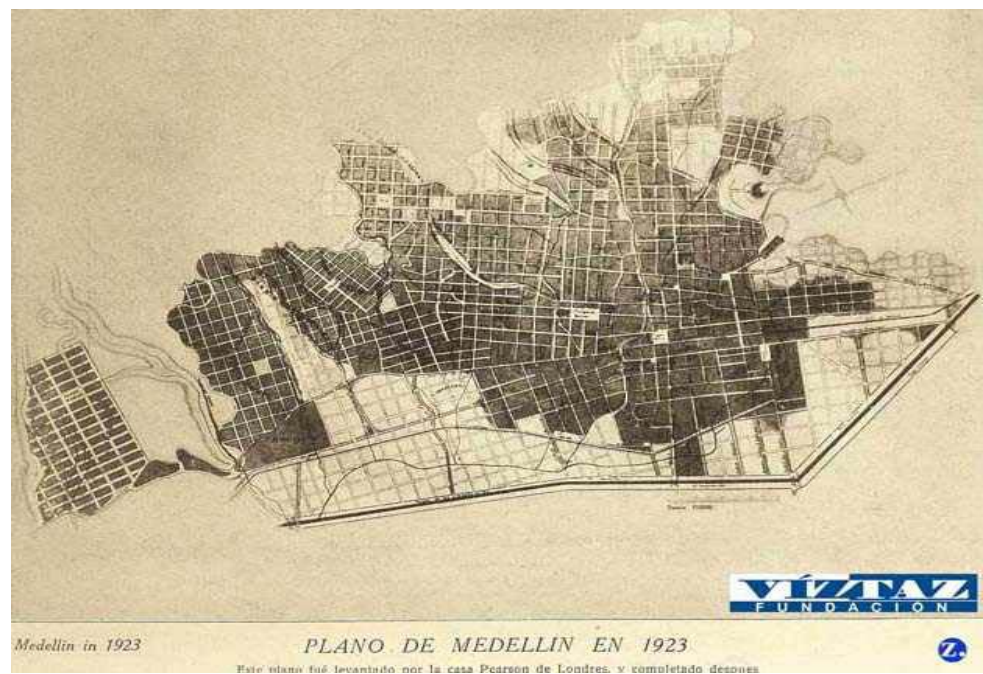


Figura 5. Plano de Medellín, 1944.

Tomado de http://www.viztaz.com.co/usvm/botones/mapas/1944.jpg

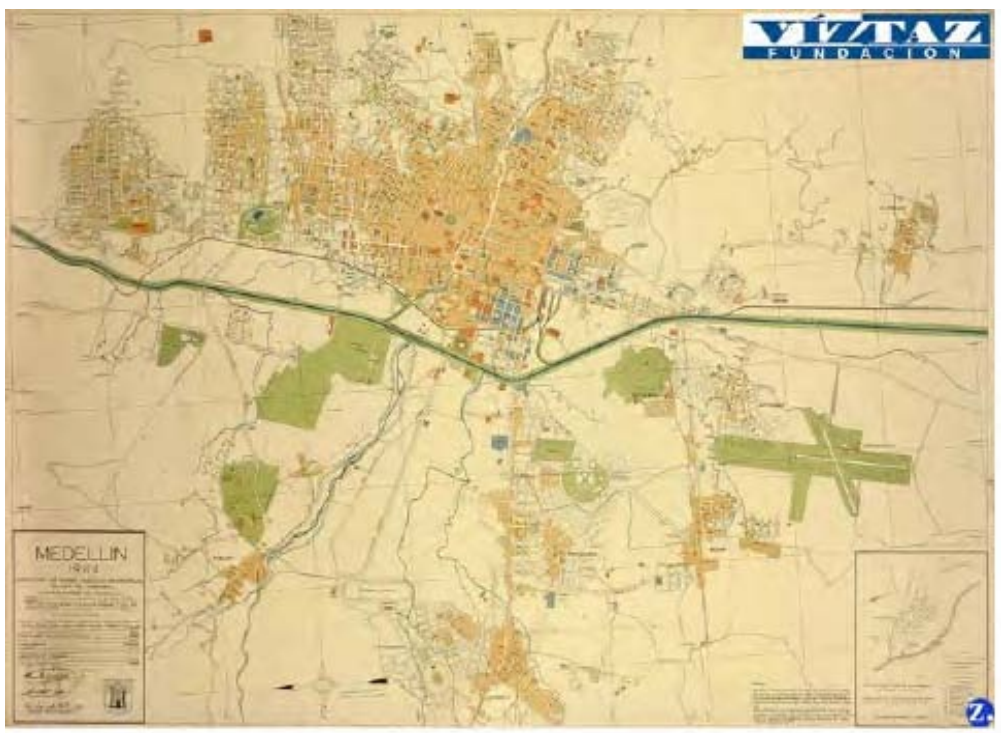

Figura 6. Plano Plan Piloto de Medellín, 1950. Wiener y Sert, 1950. Concejo de Medellín. Tomado de Galería de Imágenes. Fichero 45/45 Escuela de hábitat CEHAP Facultad de Arquitectura en http://agora.unalmed.edu.co/galeria/displayimage.php? album=77\&pos $=40$

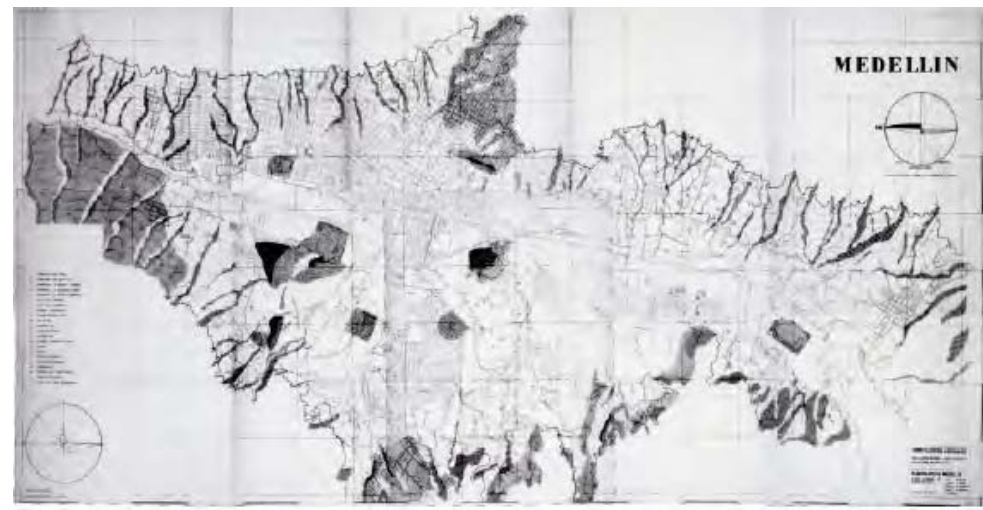


Plano de Medellín, 1980

Tomado de Perímetros urbanos. Bahamón, 2009.

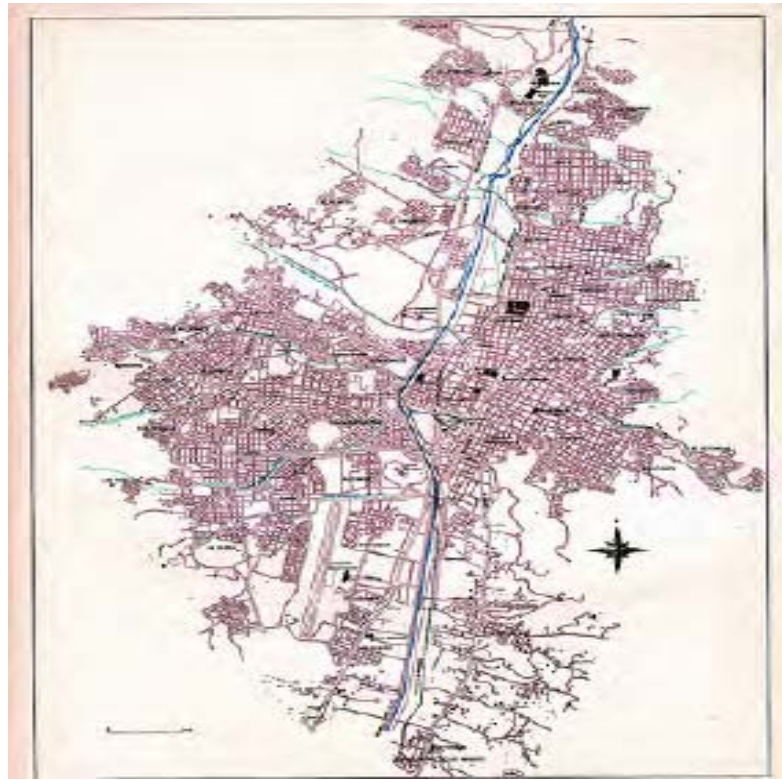

Figura 7. Plano de Medellín 1999. Tomado de Galería de Imágenes. Fichero 35/45 Escuela de hábitat CEHAP Facultad de Arquitectura en http://agora.unalmed. edu.co/galeria/ displayimage.php?album $=77 \&$ pos $=40$

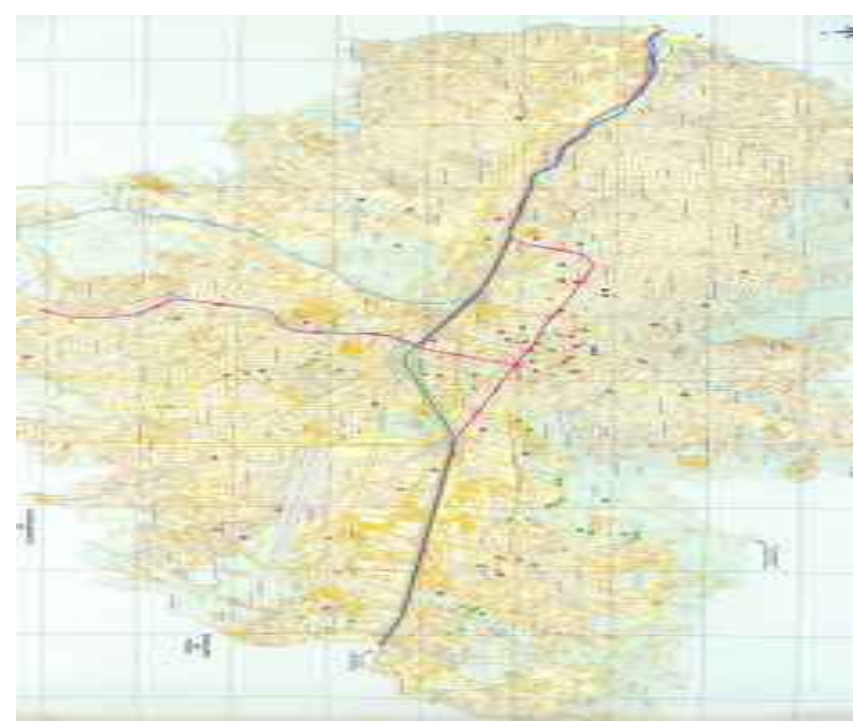


Figura 8. Medellín, 2007. Tomada de Perímetros Urbanos, Bahamón, 2009. Fuente: Historia de Antioquia y Censos del DANE

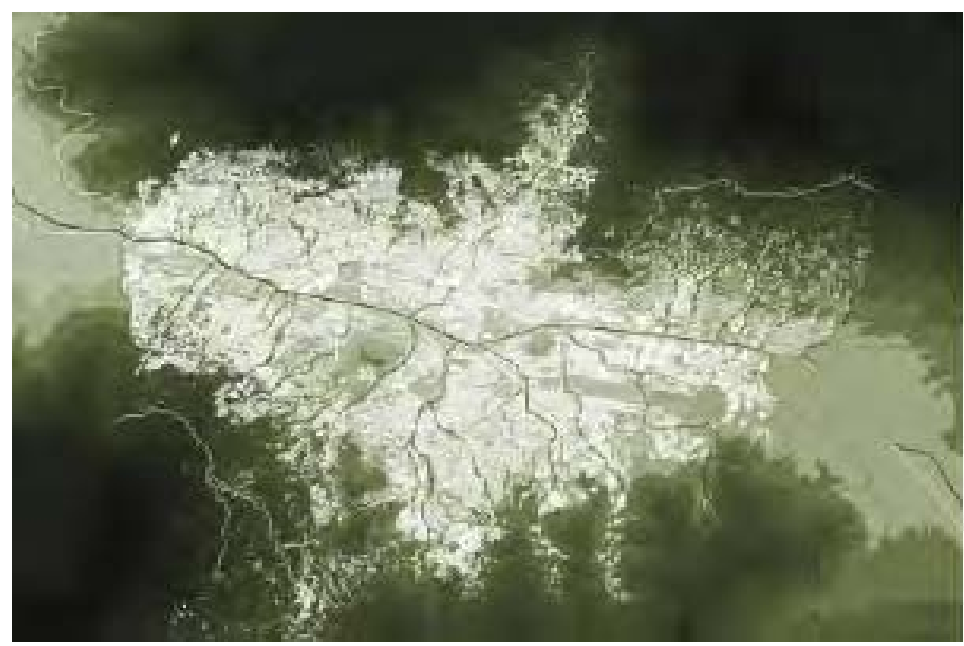

\section{Población de Medellín}

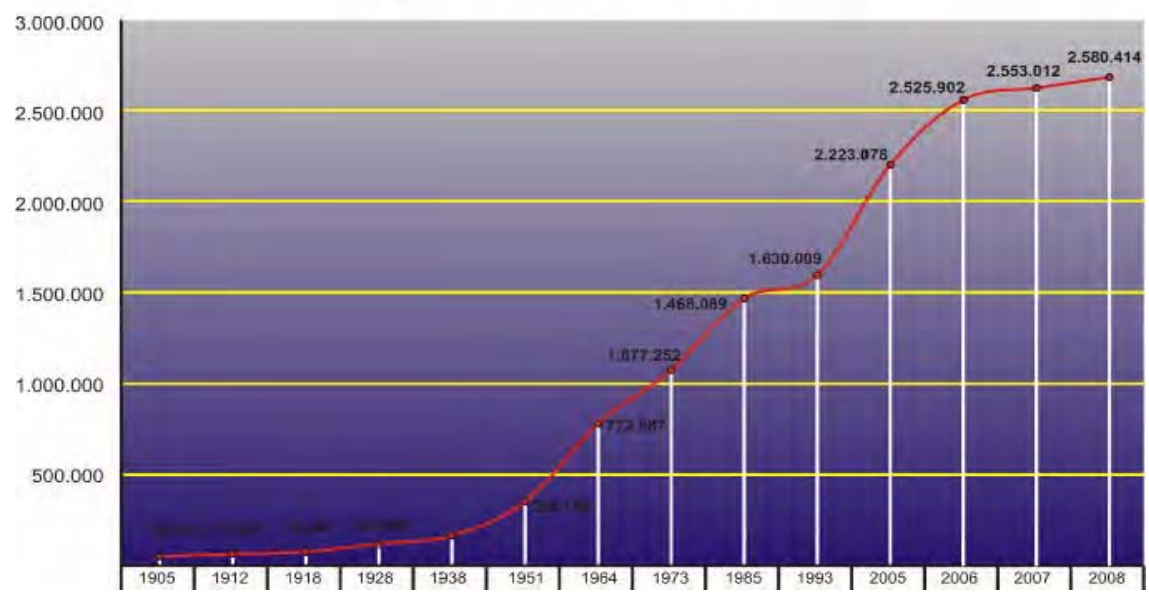

Figura 8. Tomado de Perímetros urbanos. Análisis del proceso de delimitación de espacialidades urbanas. Un estudio de caso, en Medellín. Autoría de Gabriel Enrique Bahamón Álvarez, como trabajo de tesis de investigación presentado para optar por el título de Magíster en estudios urbano - regionales en la Escuela de planeación Urbano - territorial de la facultad de Arquitectura de la Universidad nacional de Colombia, Sede Medellín, 15 de julio de 2009. 

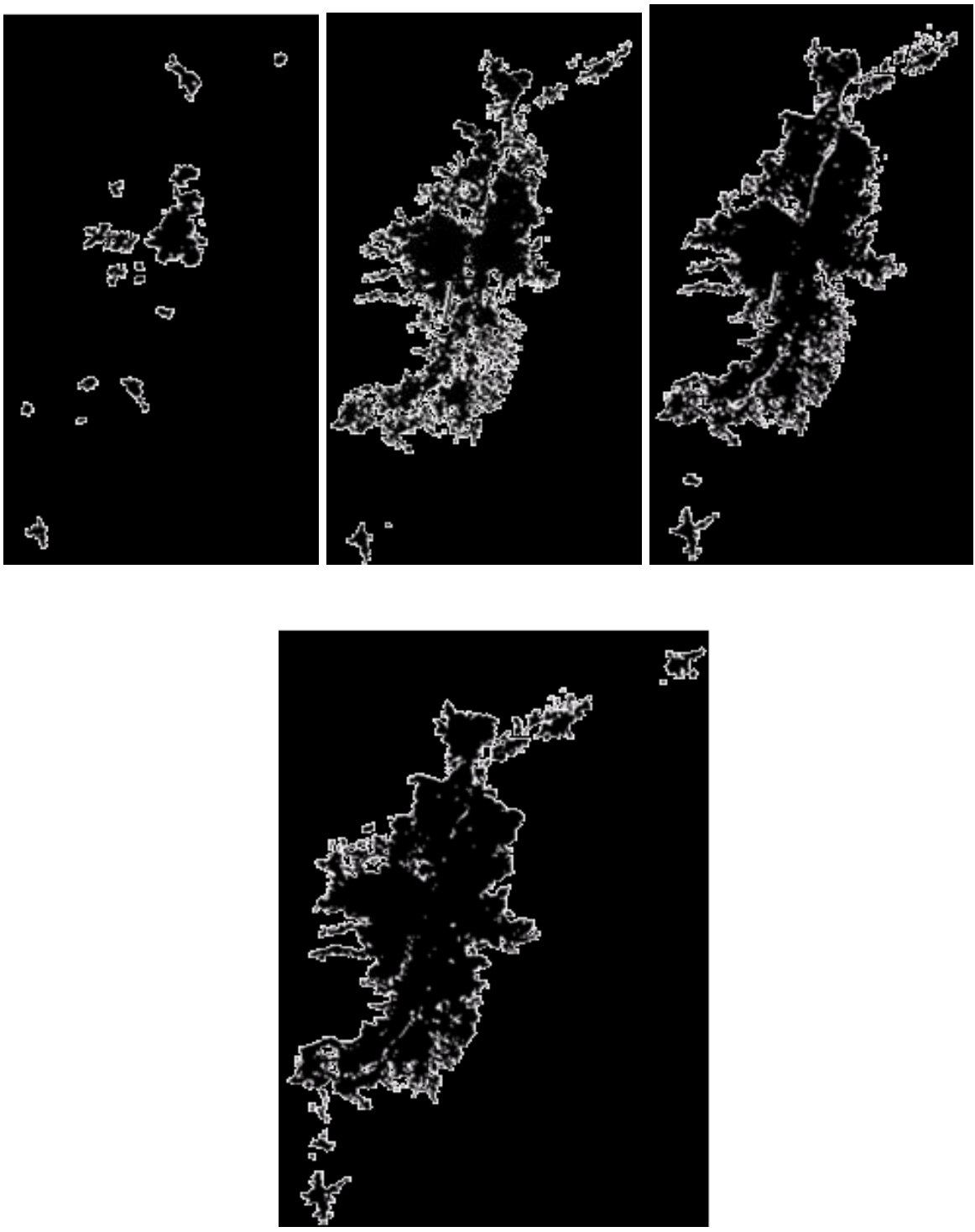

1996

Mancha de crecimiento urbano y proceso de conurbación. Estudio de la forma del crecimiento urbano de la región Metropolitana, Área Metropolitana del Valle de Aburrá, 2007, Imagen tomada de la presentación "una mirada al proceso de articulación Medellín y su Área Metropolitana desde la experiencia de otras capitales del mundo" autoría de Pedro, dentro del $5^{\circ}$ Congreso de Ciudad 2010, Medellín, 4 y 5 de octubre de 2010. 
Imagen comparativa del mismo sector del Río Medellín, antes y después de la canalización, tomada del documento "algo de Historia", en Canalización del Río Medellín, registrada en el sitio WEB. fluidos.eia.edu.co/hidraulica/.../rio_medellin/inicial.htm.
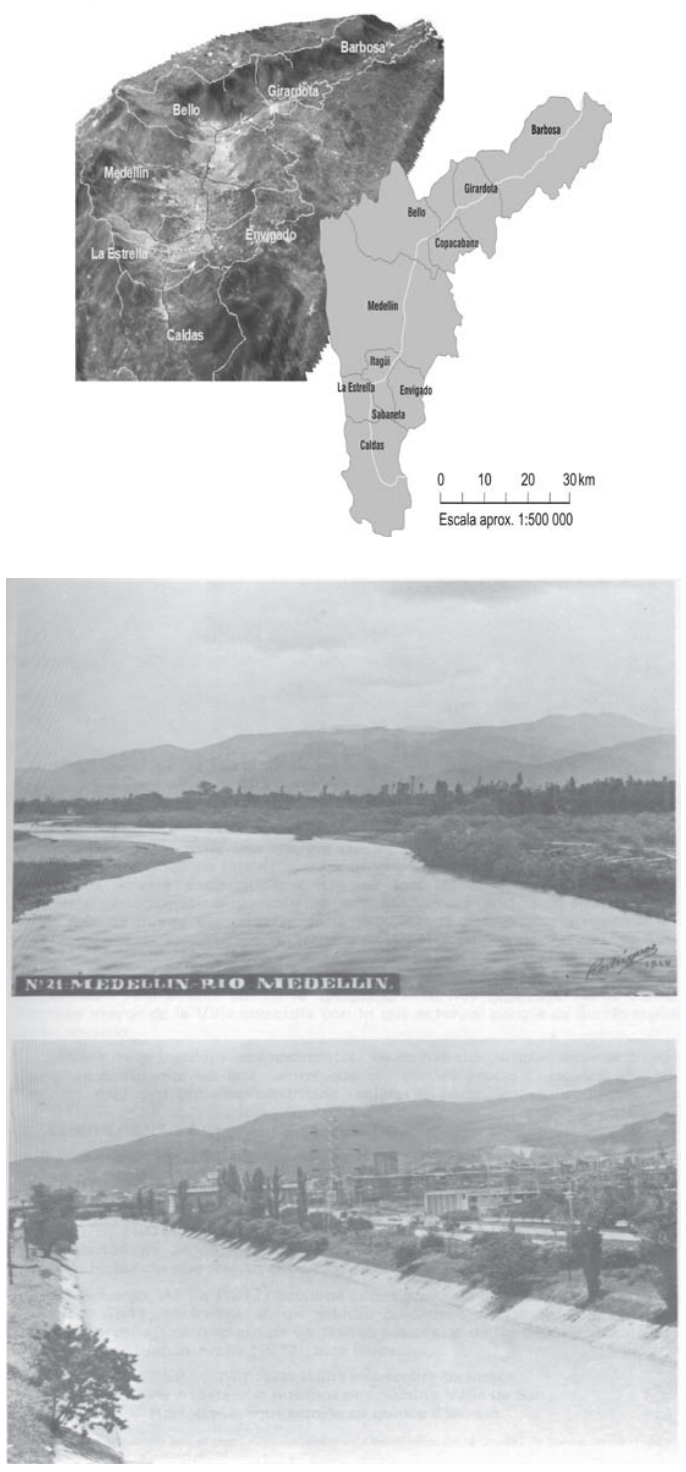
Condominios y estabilidad ecológica
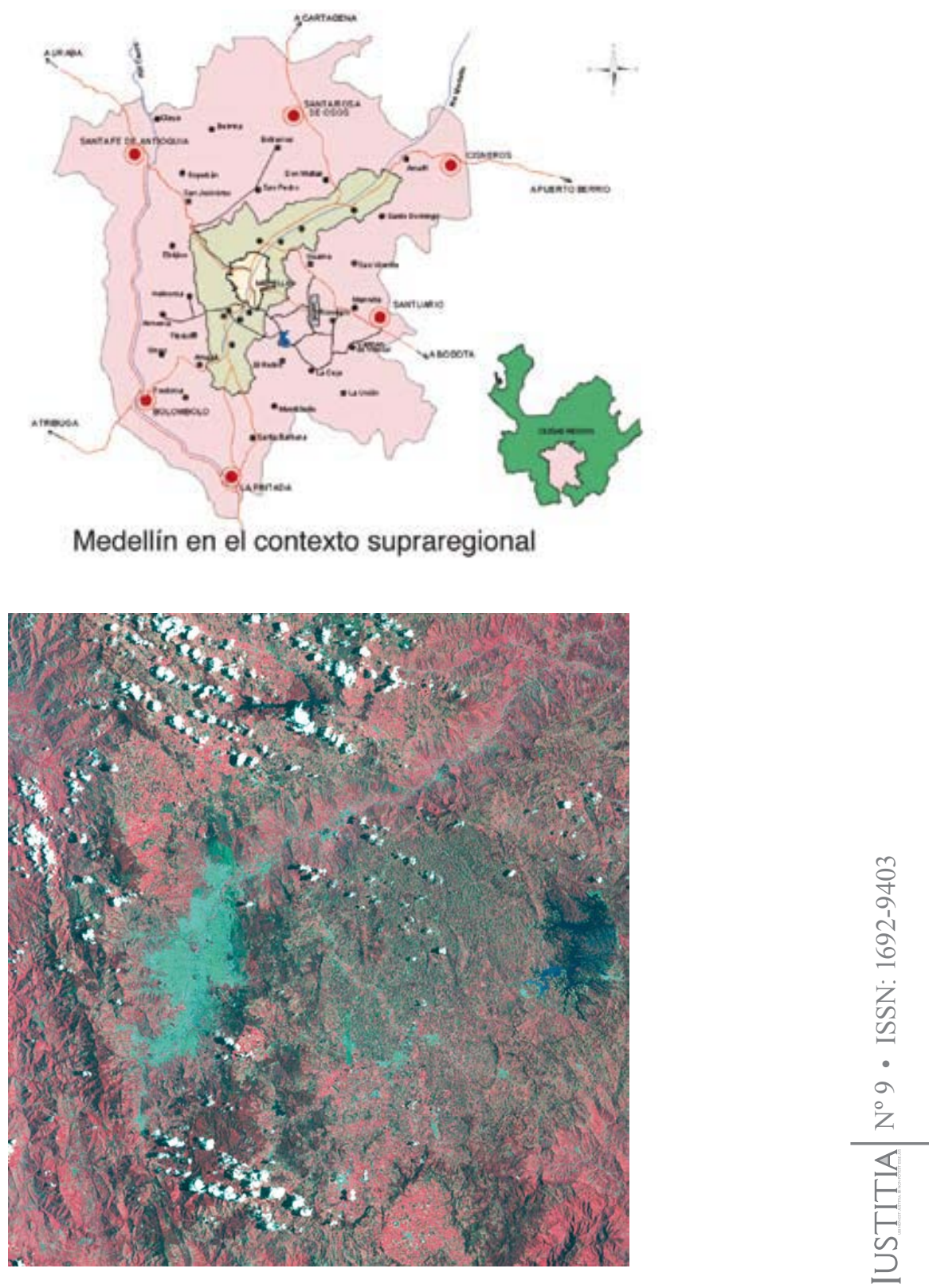

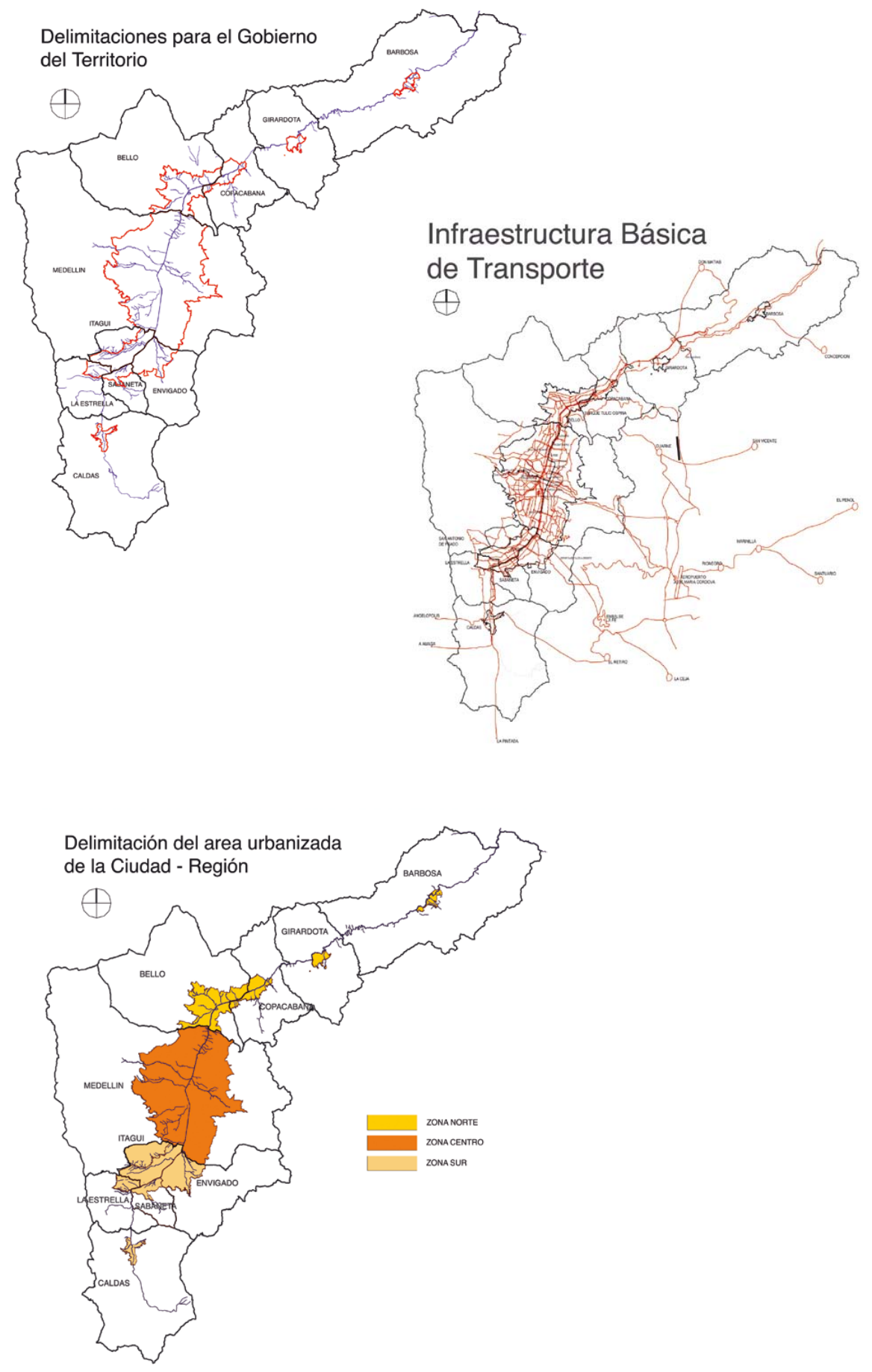